Research Article

\title{
Experimental Study on Bond-Slip Behavior of Bamboo Bolt-Modified Slurry Interface under Pull-Out Load
}

\author{
Wei Lu $\mathbb{D}^{1,2}$ Dong Zhao, ${ }^{2}$ Xiao-fei Mao, ${ }^{2}$ and $\mathrm{Yu} \mathrm{Ai}^{3}$ \\ ${ }^{1}$ School of Civil Engineering, Xi'an University of Architecture \& Technology, Xi'an, Shaanxi 710055, China \\ ${ }^{2}$ School of Science, Xi'an University of Architecture \& Technology, Xi'an, Shaanxi 710055, China \\ ${ }^{3} X i$ 'an Aerospace Remote Sensing Data Technology Co., Ltd., Xi'an, Shaanxi 710100, China \\ Correspondence should be addressed to Wei Lu; woshidabaicai866@163.com
}

Received 8 August 2017; Revised 6 November 2017; Accepted 14 November 2017; Published 8 February 2018

Academic Editor: Hossein Moayedi

Copyright (c) 2018 Wei Lu et al. This is an open access article distributed under the Creative Commons Attribution License, which permits unrestricted use, distribution, and reproduction in any medium, provided the original work is properly cited.

\begin{abstract}
This paper presents an analysis of bamboo bolt-modified slurry interfaces based on 26 in situ axial pull-out tests intended to highlight the mechanical behavior of interface under a fracture mode. Three impact factors are analyzed: anchorage length, bolt diameter, and bolt hole diameter, using the same materials of bamboo and modified slurry. The result shows that the interface between the bamboo bolt and anchoring agent is the control interface of an anchorage system, and the local behavior of the interface involves four stages: elastic, soften, friction, and decoupling. Distribution law and change trend of slippage, stress, and strain of anchoring interface along with the axial direction of an anchor bolt were analyzed. The result shows that there is effective anchoring length limit in this kind of interface, and that the complete decoupling phenomenon should not be neglected. Through a comparative analysis of the existing bond-slip model and interface bond-slip curve, and considering the correspondence of the strain-slip curve and trilinear bond-slip model simultaneously, a modified trilinear bond-slip model has been proposed. The friction section of this model is limited, and shearing stress in the complete decoupling section is zero.
\end{abstract}

\section{Introduction}

Rammed earth site is a historical building relic with soil as the main material left by ancient human activities, including residential sites, walls, and beacon towers, with a high historical, cultural, and artistic value, as shown in Figure 1. The distribution of rammed earth sites is centralized along the Silk Road in Central and East Asia, but the deterioration of cracks, sapping, and so forth is highly developed in sites (Figure 2). Therefore, corresponding reinforcement works are being carried out to deal with the emergency, with a purpose to prevent the loss of the historic and cultural information carried by the relics as a result of the potential large-scale collapses in the near future. The distribution of rammed earth sites of China is highly centralized in the northwest arid region. Due to less rainfall, occasional strong winds and sandstorms, powerful tectonic movements, and frequent seismic activities, there is a great likelihood of cracks caused by the tension and shear force. The crack normally extends throughout the site, so as to result in collapse, instability, and dislocation to the structure. Under the protection concept of a cultural relic "repair old as before," it is generally subjected to the concealed mechanic stability control technology of "anchoring" to treat the stability problems of an earthen site at present.

Different from the traditional soil slope, rammed earth sites are mostly rammed artificially. There are multiple longitudinal and vertical ramming boundaries in rammed earth structure; the cracks extend along the ramming boundaries with an extensive but organized distribution under the effect of external erosion by rain, earthquake, and so forth. According to the results of relevant scholars' studies on the material physical and mechanical properties of the rammed earth sites (such as city walls and beacon towers), the mechanical properties of the soil body of different parts of the sites show significant differences [1-3]: As a result of rainfall penetration at cracks of the sites, as well as the erosion of strong dusty winds, the dissolutionrecrystallization cycle of soluble salt, and the freezingthawing cycle of water, the cracks and exposed parts on 


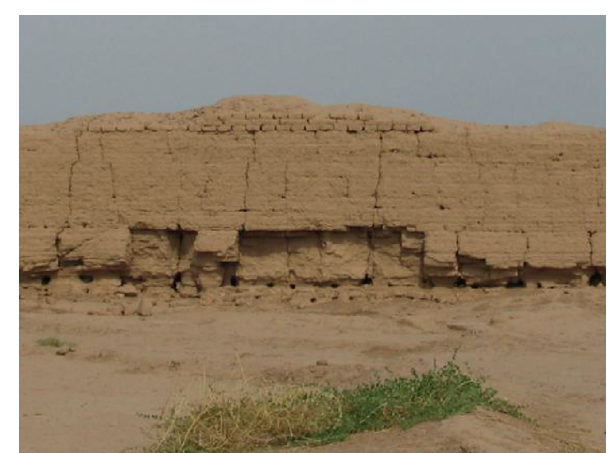

FIGURE 1: Rammed earth site of Gaochang ruin.

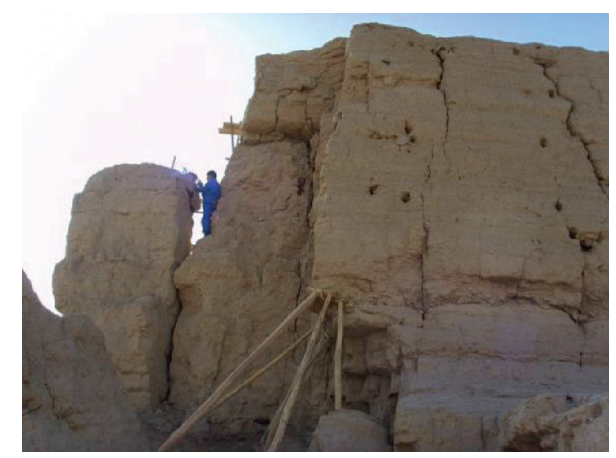

FIgURE 2: Crack propagation in an earthen site.

the surface of the sites show serious weathering and salt efflorescence, leading to the reduction of strength and the risk of peeling off. Therefore, in order to preserve the cultural information carried by the surface of the sites, the prestressing technology is limited to use in reinforcement projects for ancient rammed earth sites. On the other hand, the density of the earth inside the ruins is higher, and it can provide good hoop constraints to the anchor bolt. Therefore, the wholly grouted anchor system is usually used in the anchorage project of earthen sites.

As growing attention has been paid to the conservation of worldwide earthen heritage sites (rammed earth walls, fire beacon tower, etc.), anchorage technology is widely used to deal with the rammed earth sites' structural diseases [4-6]. However, the anchoring scheme of metal bolts and cement mortars commonly used in soil and rock slope reinforcement engineering is not suitable for anchoring of soil sites because (1) the difference in the material property between the metal bolt and the soil is so large that it is difficult for the anchoring force to be exerted, (2) the metal material is easy to react with the moisture in the soil to cause corrosion, and (3) the use of prestressed technology is restricted. The field survey results show that bamboo and timber materials are often used as reinforcing materials to improve the integrity of the rammed earth structure and its compatibility with soil was verified. Therefore, bamboo-type (or timber-type) fulllength bonded bolt has a good applicability in the soil site reinforcement.

The anchorage system is generally used for anchoring steel bars into the holes of rock and soil mass to restrain the dangerous structure. The existing research results show that the anchorage performance of the anchorage system is not only connected with bolts but also closely related to the properties of the internal and external fixing materials (or devices) and the stages of material slip failure [7]. This paper studies the full-length bonded bolt anchorage system. The bamboo bolt is bonded with soil mass through modified slurry, and load transfer mainly depends on the interface bonding effect. Therefore, the research on the interface mechanics behavior of the anchorage system is particularly important.

In recent years, the relevant scholars have made a lot of researches on the bond-slip relationship between different materials and proposed a variety of calculation models, which can be divided into two types: nonlinear model and multistage linear model. As for the anchorage interface mechanical behavior, Farmer [8] proposed the first analytical solution to the behavior of rockbolts under tensile forces. This essential work predicted that the axial load and the shear stress decrease exponentially from the loading point to the free end of the bolt before decoupling occurs. Yazici and Kaiser [9] emphasized the effect of dilatancy effect on the ultimate bond strength of the anchorage interface and developed the bond strength model (BSM) in 1990s. Short later, Benmokrane et al. [10] studied the stress distribution and evolution law of the anchorage interface by field and laboratory pull-out tests and then proposed a trilinear bondslip model for the interfacial mechanism between the bolt and grout. More recently, Li and Stillborg [11] introduced the notion of "decoupling front" and presented an analytical model through pull-out test; the model considered the decoupling mechanism, and the shear stress is assumed to be zero when the interface is completely decoupled. Fahimifar and Soroush [12] analyzed the interface interaction between grouting bolt and rock mass by using brittle behavior model and strain-softening behavior model. Wu et al. [13] analyzed the crack propagation of the anchoring system by using the double-bilinear shear-lag model, which does not consider the impact of friction section. Ren et al. [14] presented an analytical solution for predicting the full-range behavior of grouted rockbolts in tension. A trilinear bond-slip model was again considered for the rockbolt-cement grout joint interface, the model parameters are calibrated by identifying the different stages of load-displacement curves at the loading end. Ma et al. [15] and Martin et al. [16] analyzed the whole process of anchor bolt slippage by using trilinear bond-slip model, which is suitable for the interface of high strength materials such as metal and cement mortar. However, the analytical model used by Li and Stillborg [11], Ren et al. [14], Ma et al. [15], and Martin et al. [16] only focused on rockbolts without free end slip and ignored the slip of the bolt free end. Recently, Biscaia et al. [17] analyzed the mechanism behavior and debonding process of the FRP-to-concrete interface on shear tests with the FRP plate submitted to a tensile load in one of its ends, three linear and one exponential bond-slip models are employed in the numerical process, and the results are analyzed and compared. Ma et al. [18] took the residual shear stress and the complete decoupling mechanisms 
TABLE 1: Specimen classification.

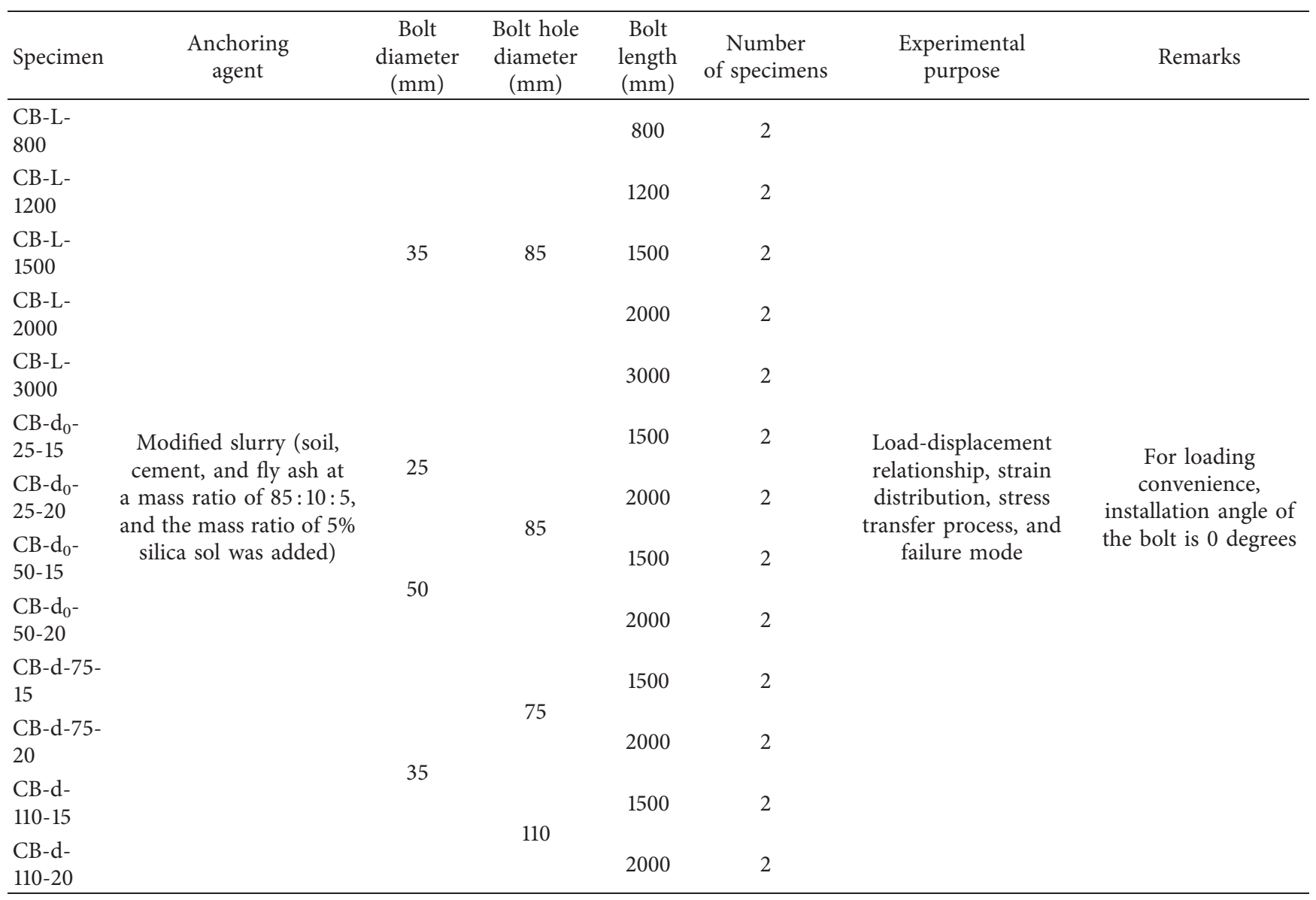

into account and presented a nonlinear bond-slip model for fully encapsulated rockbolts subjected to the tensile load in pull-out tests.

These works are fundamental and have deeply contributed to a better understanding of the behavior of anchor bolts under tension loads, which has in turn led to a higher quality design. However, in the anchorage of soil sites, bamboo-type bolts are usually featured by low elasticity, high plasticity, and good ductility $[19,20]$, and the property of the anchorage agent is different from that of the cement mortar. However, the interface mechanical behavior between the two materials conforms to the existing bond-slip model is not yet clear.

In view of the above, considering the respective effect of the anchoring length, anchor rod diameter, and anchor hole diameter on the anchorage performance, this paper conducted in situ axis pull-out test to study the mechanical behavior of bamboo bolt-modified slurry interface in earth sites, and the stress distribution law and change trend of anchor interface are analyzed according to the loaddisplacement relationship and strain monitoring data. Then, the interfacial bond-slip curves obtained from the test are compared with several existing bond-slip models; on this basis, considering the corresponding relationship between the interface strain-slip curve and the bond-slip model at different stages, an improved trilinear bond-slip model is proposed for this kind of interface. Finally, the model was validated with the result of similar studies.

\section{Materials and Methods}

2.1. Experiment Scheme. The purpose of this experiment is to analyze the bond-slip behavior of the interface between the bamboo bolt and the modified slurry. The experiment considers the effect of three factors (bolt length, bolt diameter, and bolt hole diameter) on the anchoring force, respectively. The length of the bolt is divided into 5 types: $800 \mathrm{~mm}, 1200 \mathrm{~mm}, 1500 \mathrm{~mm}, 2000 \mathrm{~mm}$, and $3000 \mathrm{~mm}$; the diameter of the bolt is divided into 3 types: $25 \mathrm{~mm}, 35 \mathrm{~mm}$, and $50 \mathrm{~mm}$; and the drilling hole diameter is divided into 3 types: $75 \mathrm{~mm}, 85 \mathrm{~mm}$, and $110 \mathrm{~mm}$. Two specimens were set for each type, and 26 specimens were in total, in which both loaddisplacement relationship and bolt surface strain are monitored. The classification of bolt specimens is shown in Table 1 .

2.1.1. Treatment of Bamboo Bolt. Due to the low strength of bamboo itself, fixture cannot be directly applied to the bamboo. Therefore, the bamboo joints at the loading end shall be opened up before experiment. The steel bars shall be inserted and firmly bonded with epoxy resin, as shown in Figure 3. The fixtures are used for exposed steel bars. The bolt specimens are shown in Figure 4. 


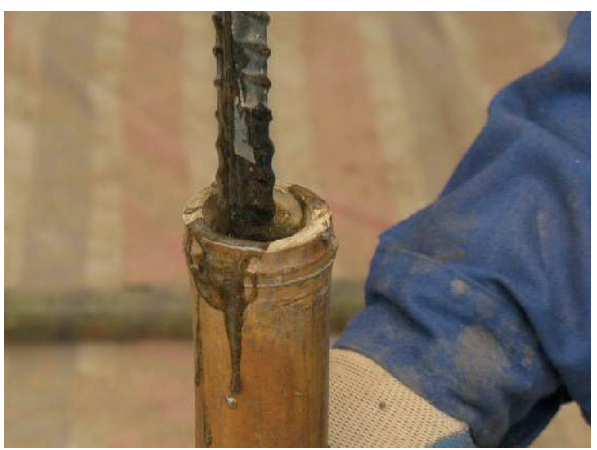

FIGURE 3: Loading steel bar installation.

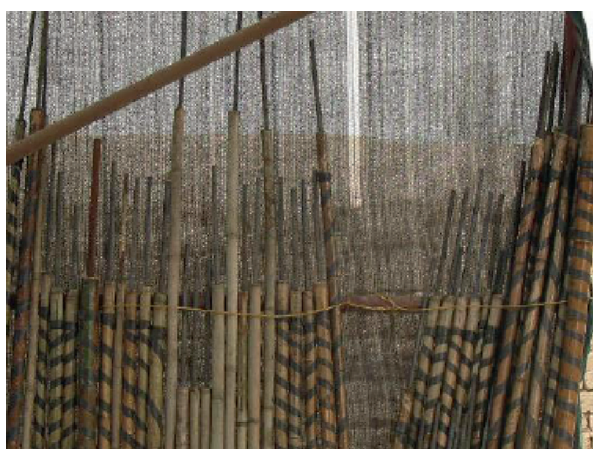

FIgURE 4: Bolt specimens.

2.1.2. Sticking of Strain Gauges. Five strain gauges (sensitivity is 0.206 ) are placed on the outer surface of the bolt at equal intervals along the anchorage length, lead and wire are welded by soldering, and they are numbered from the loading end to the anchoring end. The temperature compensating sheet is arranged at the outer surface near the midpoint of the bolt.

Before the strain gauge is pasted, the bamboo surface should be grounded with an abrasive paper into the oblique texture. The angle between the oblique texture and strain gauge direction should be $45^{\circ}$. Then, scrub the grounded part with an absorbent ball containing absolute ethyl alcohol in one direction. Paste the strain gauge immediately after the grounded part is dried naturally. In order to protect the strain gauge, coat the exposed part with moisture-proof glue and wrap it with glass fabric. The strain signals are recorded by the TDS-303 data acquisition instrument made in Japan.

2.1.3. Loading Scheme. The drawing displacement is measured by an electronic vernier caliper fixed to the tension meter with an accuracy of $0.01 \mathrm{~mm}$, as shown in Figure 5. This experiment uses center hole Jack loading, center aperture $30 \mathrm{~mm}$, height $250 \mathrm{~mm}$, maximum working capacity of bolt tension is $100 \mathrm{kN}$, and the tensile stroke is $150 \mathrm{~mm}$. The loading method is continuous loading, and each load step is $0.1 \mathrm{kN}$, until the anchorage system failure. The data acquisition device is shown in Figure 6. Considering the local hot weather, carry out curing for $30 \mathrm{~d}$ after grouting

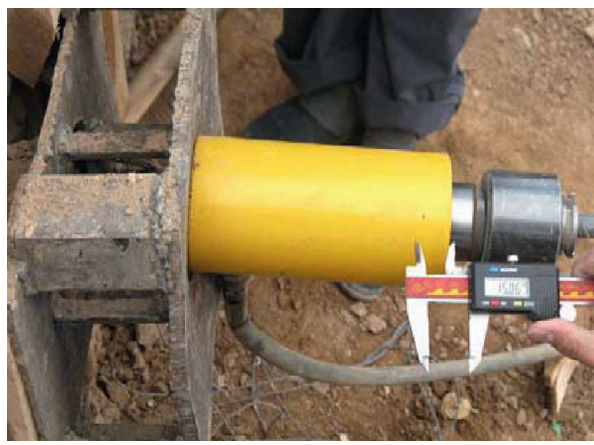

Figure 5: Vernier caliper and loading device.

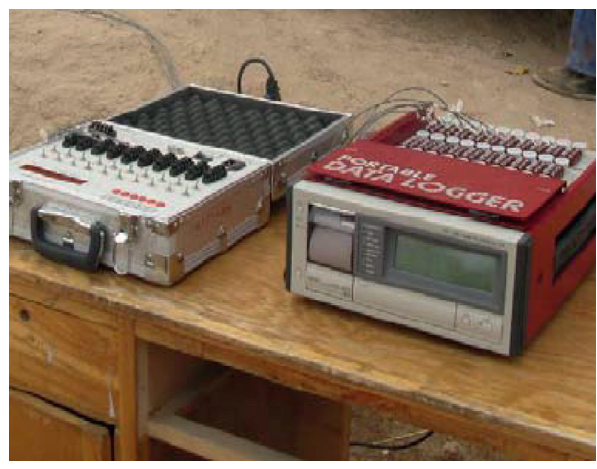

FIgure 6: Data acquisition device.

and conduct the pull-out test after the interface bonding effect is fully achieved.

2.1.4. Bolt Installation. To avoid the influence on wall stability, the pull-out test is done on the compact part of the rammed structure. The vertical and horizontal spacing of adjacent bolts are more than $2 \mathrm{~m}$, and long and short bolts are staggered to reduce the group anchoring effect. Twisting and bending should be minimized when bolts are installed into holes. Due to slurry permeation into soil and evaporation of water, slurry will shrink after curing. Therefore, a manual makeup should be done after grouting.

This experiment was carried out according to Code for design and construction of soil anchor (CECS22: 90) [21] and Technical code for building slope engineering (GB 503302013) [22].

2.2. Material Properties. Prior to the pull-out test, the physical and mechanical properties of materials used are determined by means of laboratory test. Main test methods and results are as follows.

2.2.1. Modified Slurry. In this experiment, the bamboo bolt and the rammed earth were bonded by modified slurry, and the modified slurry was prepared by soil, cement, and fly ash at a mass ratio of $85: 10: 5$ (the water-cement ratio is 0.31 ), and the mass ratio of $5 \%$ silica sol was added. The geometric 
TABLE 2: Mechanical properties of the modified slurry.

\begin{tabular}{lccccc}
\hline Number & $\begin{array}{c}\text { Compressive } \\
\text { strength }(\mathrm{MPa})\end{array}$ & $\begin{array}{c}\text { Mean value of compressive } \\
\text { strength }(\mathrm{MPa})\end{array}$ & $\begin{array}{c}\text { Poisson's } \\
\text { ratio }\end{array}$ & $\begin{array}{c}\text { Compressive modulus } \\
\left(\mathrm{N} / \mathrm{mm}^{2}\right)\end{array}$ & $\begin{array}{c}\text { Mean value of compressive } \\
\text { modulus }\left(\mathrm{N} / \mathrm{mm}^{2}\right)\end{array}$ \\
\hline 1 & 3.21 & & & 62.35 & 61.26 \\
2 & 2.25 & 2.63 & 0.21 & 55.66 & 65.78 \\
3 & 2.43 & & & 6 & \\
\hline
\end{tabular}

TAвLE 3: Physical and mechanical indexes of undisturbed rammed earth (mean).

\begin{tabular}{|c|c|c|c|c|c|c|c|}
\hline Specimen & $\begin{array}{l}\text { Wet bulk density } \\
\left(\mathrm{g} / \mathrm{cm}^{3}\right)\end{array}$ & $\begin{array}{l}\text { Dry bulk density } \\
\left(\mathrm{g} / \mathrm{cm}^{3}\right)\end{array}$ & $\begin{array}{c}\text { Water content } \\
(\%)\end{array}$ & $\begin{array}{l}\text { Liquid limit } \\
\text { (\%) }\end{array}$ & $\begin{array}{l}\text { Plastic limit } \\
(\%)\end{array}$ & $\begin{array}{l}\text { Porosity } \\
\text { (\%) }\end{array}$ & $\begin{array}{l}\text { Saturation } \\
(\%)\end{array}$ \\
\hline $\begin{array}{l}\text { Undisturbed rammed } \\
\text { earth }\end{array}$ & 1.90 & 1.85 & 2.70 & 46 & 24 & 0.30 & 21.60 \\
\hline
\end{tabular}

TABLE 4: Compression modulus and compressive strength of undisturbed rammed earth.

\begin{tabular}{lccccc}
\hline Specimen & Number & $\begin{array}{c}\text { Compressive } \\
\text { strength }(\mathrm{MPa})\end{array}$ & $\begin{array}{c}\text { Mean value of compressive } \\
\text { strength }(\mathrm{MPa})\end{array}$ & $\begin{array}{c}\text { Compressive } \\
\text { modulus }\left(\mathrm{N} / \mathrm{mm}^{2}\right)\end{array}$ & $\begin{array}{c}\text { Mean value of compressive } \\
\text { modulus }\left(\mathrm{N} / \mathrm{mm}^{2}\right)\end{array}$ \\
\hline Undisturbed & 1 & 1.94 & & 30.32 & 30.48 \\
rammed earth & 2 & 1.83 & 1.92 & 28.87 & 32.25 \\
\hline
\end{tabular}

dimension of the specimen is $7.07 \mathrm{~mm} \times 7.07 \mathrm{~mm} \times 7.07 \mathrm{~mm}$. The compressive strength and compressive modulus are measured 34 days after curing. The mechanical properties of the modified slurry are shown in Table 2.

2.2.2. Undisturbed Rammed Earth. The undisturbed rammed soil is from northwest corner of the walls in the ancient city of Gaochang, Xinjiang, China (core sampling) [4]. The soil is made as the cube sample with the geometric dimension of $70 \mathrm{~mm}$ and $7.07 \mathrm{~mm}$ and tested in accordance with the Standard for Soil Test Methods (GB/T50123-1999) [23]. Physical and mechanical properties of undisturbed rammed earth are shown in Tables 3 and 4.

2.2.3. Bamboo Bolt. The bamboo bolt sample is a section of bamboo which is straight without defects, with a relatively thick wall and relatively small difference in section diameter. The test sample is prepared according to Testing methods for physical and mechanical properties of bamboos (GB/T 15780-1995) [24] and Test method for physical and mechanical properties of bamboo for construction (JG/T 199-2007) [25]; the sample moisture content is about $11 \% \sim 12 \%$.

(1) Tensile strength parallel to grain and tensile modulus of elasticity

The CSS- 88100 electronic universal testing machine produced by Changchun Research Institute for Testing Machines is used in the test. The specimen is destroyed within $60-90 \mathrm{~s}$ by means of uniform single-stage loading. As the specimen in the gauge section is weak, the parts prone to cause stress concentration, such as grooves, scratches, and sharp corners, should be minimized in the fabrication process. The test process is shown in Figure 7. The tensile

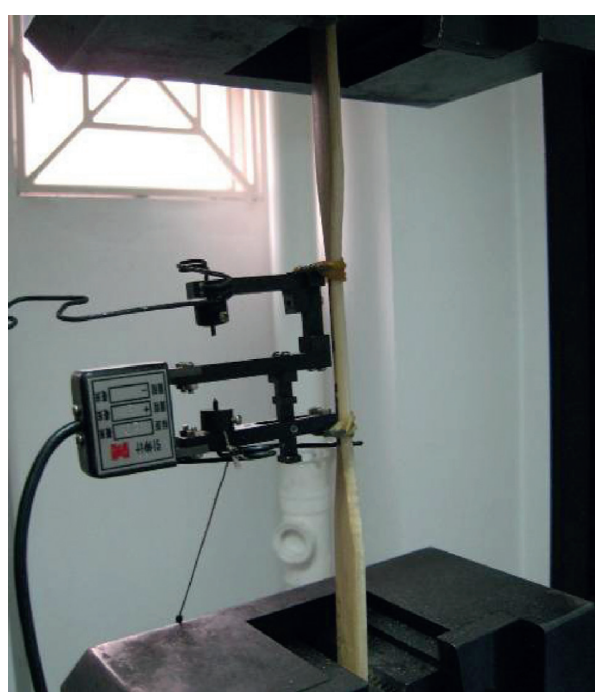

FIgURE 7: Tensile strength test.

strength parallel to the grain and the elasticity modulus of bamboo are shown in Table 5 .

(2) Bending strength

In the bending strength test, the specimen is cut in the grain direction into $160 \mathrm{~mm} \times 10 \mathrm{~mm} \times 6 \mathrm{~mm}$ (length $\times$ width $\times$ wall thickness). Grind the fulcrum and loading surface of the bamboo before the test to avoid slippage in the loading process. The test method is similar to loading on the midspan of the simply supported beam, as shown in Figure 8 . The fulcrum spacing is $120 \mathrm{~mm}$, and the load is increased uniformly in one direction on the midspan to destroy the specimen within 60-90 s. The bending strength of the bamboo is shown in Table 6. 
TABLE 5: Tensile strength and elastic modulus of bamboo.

\begin{tabular}{|c|c|c|c|c|c|c|c|c|c|c|}
\hline Number & $\begin{array}{l}\text { Gauge } \\
\text { length } \\
(\mathrm{mm}) \\
\end{array}$ & $\begin{array}{l}\text { Width } \\
(\mathrm{mm})\end{array}$ & $\begin{array}{l}\text { Thickness } \\
(\mathrm{mm})\end{array}$ & $\begin{array}{l}\text { Breaking } \\
\text { load }(\mathrm{kN})\end{array}$ & $\begin{array}{l}\text { Breaking } \\
\text { strain (\%) }\end{array}$ & $\begin{array}{c}\text { Mean value of } \\
\text { breaking } \\
\text { strain (\%) } \\
\end{array}$ & $\begin{array}{l}\text { Tensile } \\
\text { strength } \\
(\mathrm{MPa})\end{array}$ & $\begin{array}{c}\text { Mean value of } \\
\text { tensile strength } \\
(\mathrm{MPa})\end{array}$ & $\begin{array}{c}\text { Elasticity } \\
\text { modulus } \\
(\mathrm{MPa})\end{array}$ & $\begin{array}{l}\text { Mean value of } \\
\text { elasticity } \\
\text { modulus (MPa) }\end{array}$ \\
\hline 1 & & 4.64 & 2.02 & 2.86 & 2.65 & & 304.9 & & $1.15 E 4$ & \\
\hline 2 & & 5.00 & 2.06 & 3.19 & 2.46 & & 309.7 & & $1.26 E 4$ & \\
\hline 3 & 50 & 4.44 & 2.06 & 2.99 & 2.44 & 2.68 & 327.6 & 306.5 & $1.34 E 4$ & $1.16 E 4$ \\
\hline 4 & & 4.50 & 1.90 & 2.61 & 2.58 & & 305.3 & & $1.18 E 4$ & \\
\hline 5 & & 4.56 & 1.96 & 2.55 & 3.27 & & 285.2 & & $0.87 E 4$ & \\
\hline
\end{tabular}

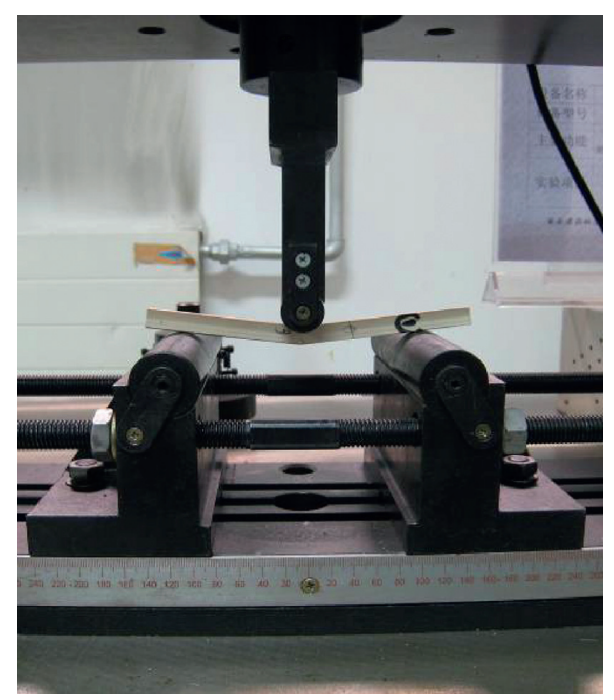

FIGURE 8: Bending strength test.

TABLE 6: Bending strength of bamboo.

\begin{tabular}{lcccccccc}
\hline Number & $\begin{array}{c}\text { Fulcrum } \\
\text { spacing } \\
(\mathrm{mm})\end{array}$ & $\begin{array}{c}\text { Thickness } \\
(\mathrm{mm})\end{array}$ & $\begin{array}{c}\text { Width } \\
(\mathrm{mm})\end{array}$ & $\begin{array}{c}\text { Breaking } \\
\text { load }(\mathrm{kN})\end{array}$ & $\begin{array}{c}\text { Bending } \\
\text { strength }^{*} \\
(\mathrm{MPa})\end{array}$ & $\begin{array}{c}\text { Mean value of } \\
\text { bending strength } \\
(\mathrm{MPa})\end{array}$ & $\begin{array}{c}\text { Fracture } \\
\text { deflection } \\
(\mathrm{mm})\end{array}$ & $\begin{array}{c}\text { Mean value of fracture } \\
\text { deflection }(\mathrm{mm})\end{array}$ \\
\hline 1 & 120 & 5.6 & 10.68 & 0.76 & 214.17 & & 7.178 \\
2 & 120 & 5.52 & 10.62 & 0.75 & 216.84 & & 7.285 & 7.102 \\
3 & 120 & 5.62 & 10.06 & 0.67 & 212.04 & & 7.022 & 6.923 \\
4 & 120 & 5.57 & 10.38 & 0.73 & 218.95 & & \\
\hline
\end{tabular}

* The bending strength is calculated by $\sigma_{b}=3 P_{\max } l / 2 b h^{2}$, where $P_{\max }$ is the failure load, $l$ is the fulcrum spacing, $b$ is the bamboo wall thickness, and $h$ is the specimen width.

\section{Results and Discussion}

3.1. Applicability of Bamboo/Wood Materials in Earthen Site Reinforcement. The ruins of rammed earth structures in northwest China are in large quantities with centralized distribution, and some of them contain wooden structures, such as plant interlayers or log skeletons, as shown in Figure 9. The survey result shows that, after the effect of natural force (such as wind, rain, and earthquake) for thousands of years, there are many serious structural diseases (such as undercutting and cracks) in rammed earth sites, which have posed a serious threat to the stability of the sites. Thanks to the tension and stabilizing effects of wooden structures, the sites with wooden structures are often less damaged than pure rammed earth. Besides, the wood material in the sites still has a certain intensity and can be well compatible with the soil mass. This has fully reflected the excellent durability and stability of wood materials in earthen site reinforcement.

Considering the cultural relic attribute of earth sites, the nonprestressed fully grouted anchor system is often used to reinforce earthen sites, and the anchoring system achieves the purpose of stabilizing the endangered site by mechanical action between three kinds of materials, namely, anchor bolt, anchor agent, and rammed earth, as shown in Figure 10.

In cultural heritage protection, it is a common practice to reinforce endangered sites with traditional materials and technologies. Following this principle, scholars have made lots of trials on anchor rod materials, mainly including ribbed 


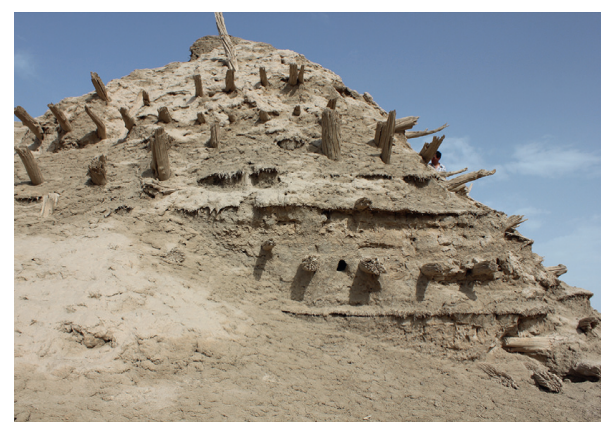

(a)

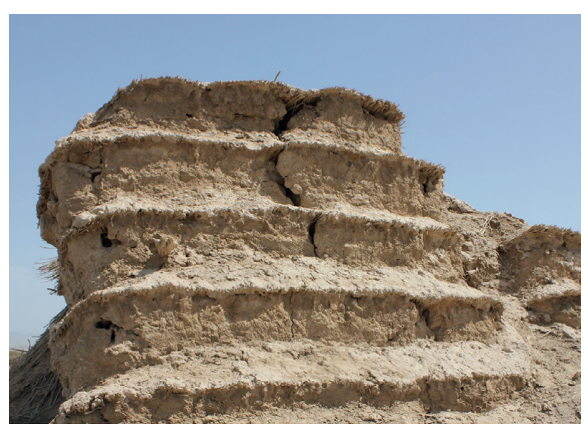

(b)

Figure 9: Remaining wooden structures in earthen sites in arid regions. (a) Log skeletons. (b) Plant interlayers.

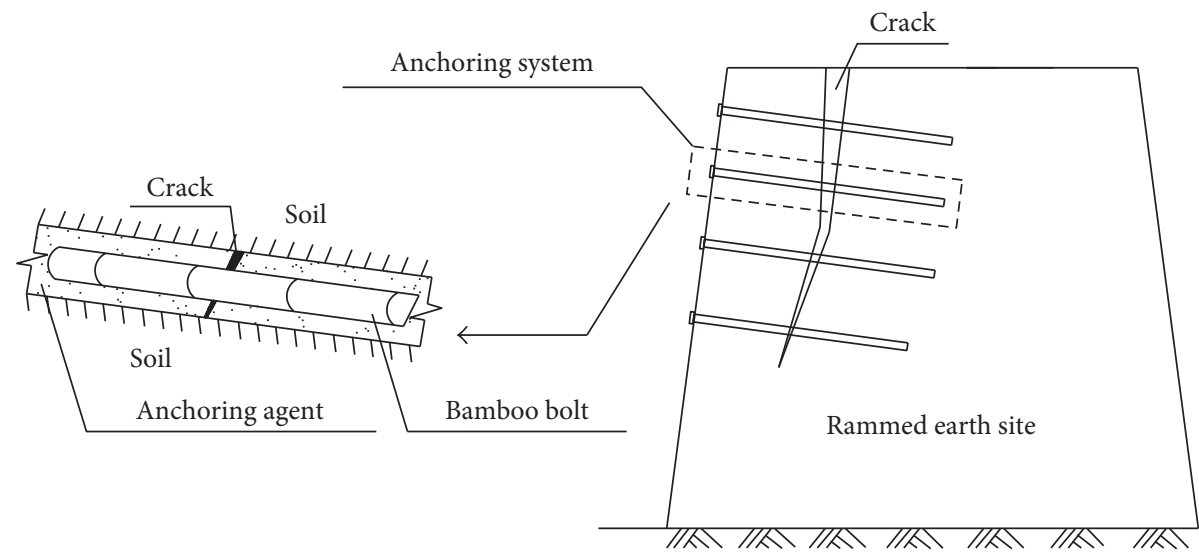

FIGURE 10: Schematic diagram of an anchor bolt-reinforced earthen site.

bar [26], thin-wall steel tube [26], bamboo/wood bolt [27, 28], bamboo-steel composite bolt [29], and GFRP bolt [30].

The results show that the stiffness of the traditional ribbed bar is much larger than that of the weathered earthen sites, the deformation between metal and soil is difficult to coordinate, and it is hard to exert the bar strength; moreover, the metal material is prone to corrosion, so its service life is very short compared with the earthen sites. Therefore, the metal anchors are not suitable for the anchorage of earthen sites.

The wood bolt anchoring system shows both tensionand pressure-type anchor features, which has the deformation characteristics of low elasticity, high plasticity, and high elongation; the anchoring effect is similar to the soil reinforcement, which can improve the integrity and selfstabilization ability of sites effectively.

With a larger diameter than the white wax bolt, the bamboo bolt has a sufficient contact area with the anchoring agent. Moreover, bamboo joints have improved the mechanical lock effect of the interface, and due to the dilatancy effect of the variable cross section, the bolt has the characteristics of the pressure-type anchor. Therefore, the anchoring performance of the bamboo bolt system is better.

The bamboo-steel composite bolt has creatively solved the problem of metal corrosion. At the same time, the tensile strength of metal materials can be brought into full play by the layer-to-layer transfer of interfacial shear stress, but the high cost has limited its large-scale application.

A GFRP bolt has the best mechanical properties and stability, but it needs to be bonded with cement mortar, which differs largely from the soil body in mechanical properties and showed poor compatibility with soil. Therefore, new anchor agents are still needed to be developed to meet the needs of site protection.

The above analysis shows that soil and wood are the main materials of ancient rammed earth sites. The existence of a great number of ancient rammed earth structures is sufficient to prove the good compatibility and durability of the two. Using bamboo/wood materials as the body of the anchor bolt is in line with the protection concept of reinforcing the sites with traditional materials. In addition, as bamboo/wood materials are more compatible with the earth site, it can provide sufficient anchoring force through a large bonding area. Therefore, bamboo/wood materials and its derived materials are more suitable for the reinforcement of earth sites.

3.2. Failure Mode. The test mainly includes three failure modes: (1) bamboo bolt-modified slurry interface slip failure (Figure 11(a)), (2) modified slurry-soil interface slip failure (Figure 11(b)), and (3) bamboo splitting at the loading end (Figure 11(c)). Among them, the first failure mode is the 


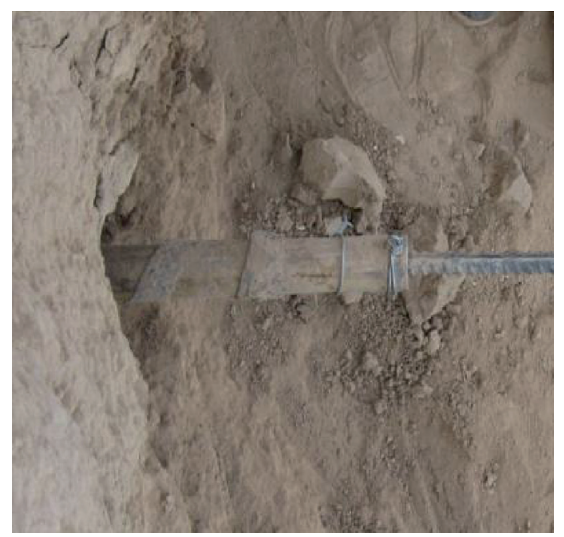

(a)

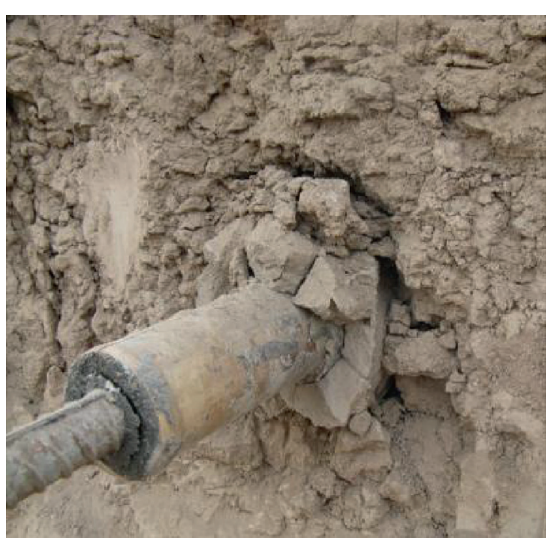

(b)

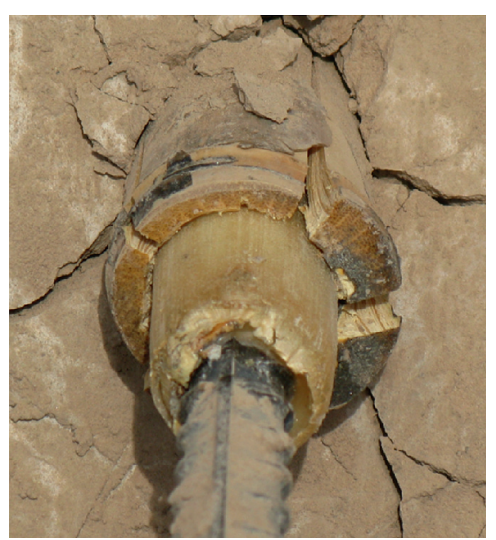

(c)

FIGURE 11: Failure mode: (a) bamboo bolt-modified slurry interface slip failure; (b) modified slurry-soil interface slip failure; (c) bamboo splitting at the loading end.

TABLE 7: Failure modes of bolt specimens.

\begin{tabular}{|c|c|c|c|c|}
\hline Specimens & Bolt length $(\mathrm{mm})$ & Bolt diameter $(\mathrm{mm})$ & Drilling hole diameter $(\mathrm{mm})$ & Failure modes \\
\hline \multirow{3}{*}{ CB-L } & $\begin{array}{l}800,1200,1500 \\
2000,3000\end{array}$ & \multirow{3}{*}{35} & \multirow{3}{*}{85} & $\begin{array}{c}\text { Bolt-modified slurry interface failure }+ \text { crushing } \\
\text { of modified slurry }\end{array}$ \\
\hline & 2000 & & & $\begin{array}{l}\text { Modified slurry-soil interface failure and soil } \\
\text { loosening of ruins around anchor holes }\end{array}$ \\
\hline & 800 & & & Bamboo splitting at the loading end \\
\hline \multirow{3}{*}{ CB- $\mathrm{d}_{0}$} & 1500 & 25 & \multirow{3}{*}{85} & Bolt-modified slurry interface failure \\
\hline & 1500,2000 & 25,50 & & $\begin{array}{l}\text { Slip failure of two interfaces + crushing of } \\
\text { modified slurry }\end{array}$ \\
\hline & 2000 & 50 & & $\begin{array}{c}\text { Slipping of two interfaces and bamboo splitting at } \\
\text { the loading end }\end{array}$ \\
\hline \multirow[b]{2}{*}{ CB-d } & 1500,2000 & \multirow[b]{2}{*}{35} & 75,110 & Bolt-modified slurry interface failure \\
\hline & 2000 & & 75 & $\begin{array}{l}\text { Slip failure of two interfaces + crushing of } \\
\text { modified slurry }\end{array}$ \\
\hline
\end{tabular}

most common, especially for specimens with short anchorage length. The second failure mode is common in specimens with long anchorage length. Such specimens are generally in full contact with modified slurry, resulting in small displacement to failure and large anchorage force. In the third failure mode, failure is mainly caused by insufficient circumferential constraints in the fabrication process, and the failure of some specimens is accompanied by soil loosening in the process of load increase, which may be related to the anchoring location and ramming quality. It should be noted that the failure modes mentioned above may coexist during the experiment.

The loading end of the first test bolt (CB-L-800a) is split too early under the pull-out load and shear dilation effect, as the circumferential constraints are not provided. Therefore, the epoxy resin is pulled out with steel bars, and the valid data are not obtained. In the follow-up specimen fabrication, the loading end of the bamboo is tightened with steel wires or carbon fiber cloth in the circumferential direction, which effectively inhibits such failure.

Table 7 shows the main failure mode of each specimen in the test. According to the results, almost all specimens have the obvious bolt-modified slurry interface slip, and some crushed slurry is pulled out. If the anchorage length is enough and the bolts are fully bonded with the modified slurry, the slip failure of the bolt-modified slurry interface is generally accompanied by the slip of the modified slurry-soil interface. However, the slippage of latter is far less than the former, approximately $1 / 50$ to $1 / 10$.

3.3. Load-Displacement Curve. The test results show that, depending on the anchorage length of bolts, the loaddisplacement curve of the specimen is basically divided into two types: similar to linear growth and with an obvious inflection point. Therefore, in this paper, the samples are divided into two categories depending on whether the anchorage length $(L)$ exceeds the effective anchorage length $\left(L_{\text {eff }}\right)$ : (1) short bolt $\left(L<L_{\text {eff }}\right)$ and (2) long bolt $\left(L \geq L_{\mathrm{eff}}\right)$.

Figures 12 and 13 show the load-displacement curve of short bolt $\left(L<L_{\text {eff }}\right)$ and long bolt $\left(L \geq L_{\text {eff }}\right)$, respectively. The CB-L-800a specimen is not presented in Figure 12(a).

According to Figures 12 and 13, the bolt length, bolt diameter, and drilling hole diameter have great influence on the anchorage performance. 


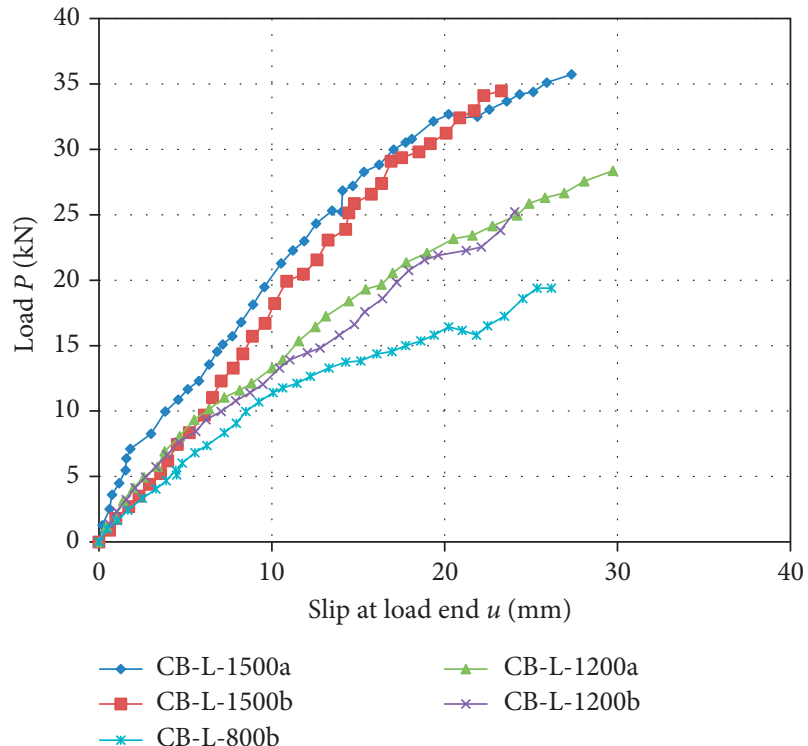

(a)

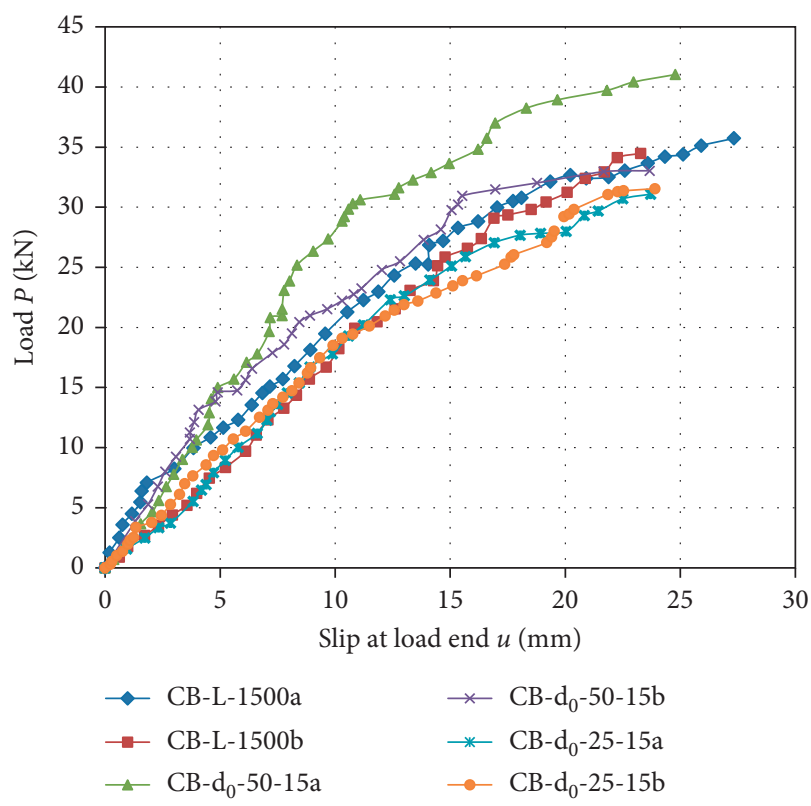

(c)

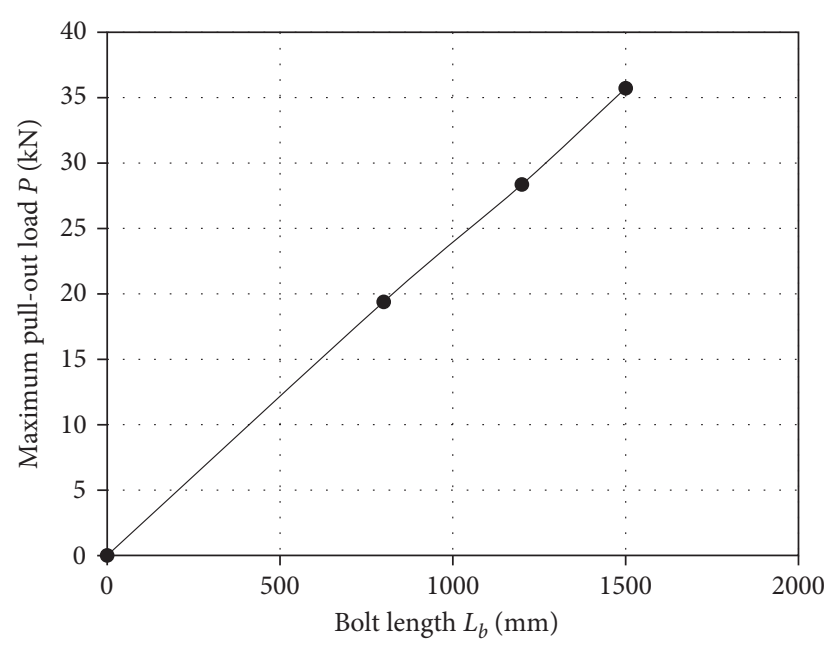

(b)

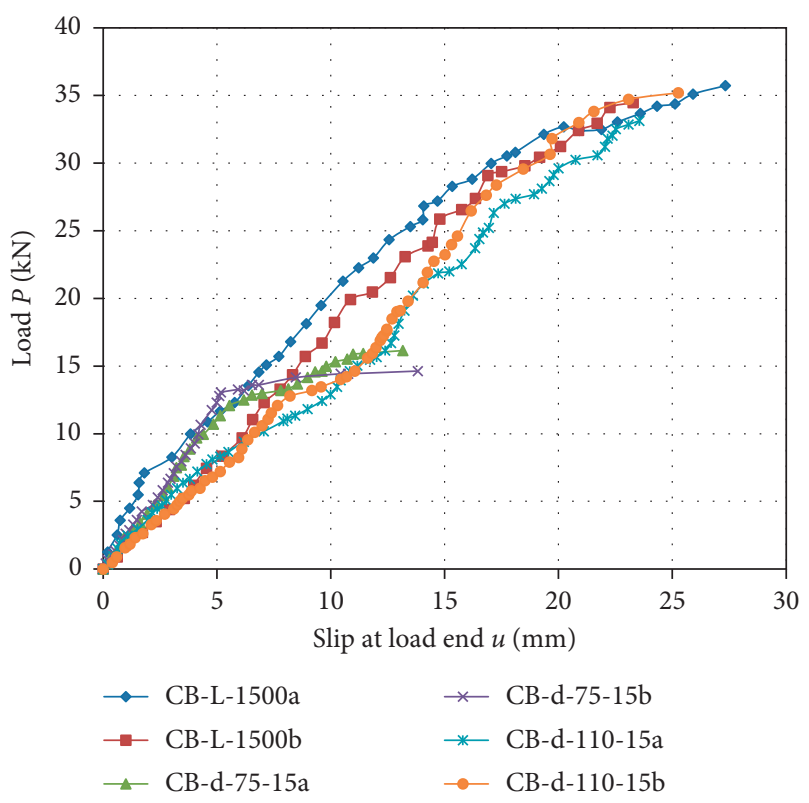

(d)

FIGURE 12: Load-displacement curve of short bolt specimens $\left(L<L_{\text {eff }}\right)$. (a) Different bolt lengths. (b) Maximum pull-out load-bolt length relationship. (c) Different bolt diameters. (d) Different bolt hole diameters.

3.3.1. Bolt Length. According to Figure 12(a), it can be seen that the curve shape of the specimens with same anchoring length is similar to each other, but the maximum pull-out load under different anchorage lengths is quite different. When the anchoring length is $1.2 \mathrm{~m}$, the maximum pull-out load increases by about $46.3 \%$ compared with that of the anchoring length of $0.8 \mathrm{~m}$. When the anchoring length is $1.5 \mathrm{~m}$, the maximum pull-out load increases by about $26 \%$ compared with that of the anchoring length of $1.2 \mathrm{~m}$. The displacement of the loading end increases linearly with the load increase, and load-displacement curve has no steady stage. The results show that the length of the three kinds of anchorage does not exceed the effective anchorage length. Figure 12(b) shows the trend of maximum pullout load versus anchor length when $L<L_{\text {eff }}$ is applied.

The load-displacement curve of the long bolt has an obvious linear section, a transition section, and a smooth section (shown as Figure 13(a)). The shapes and the peak loads of the curves are similar before reaching the peak values; the maximum load is about $40.5 \mathrm{kN}$, indicating that the anchorage length $L \geq 2 \mathrm{~m}$ has exceeded the effective anchorage length, while the ultimate anchoring force no 


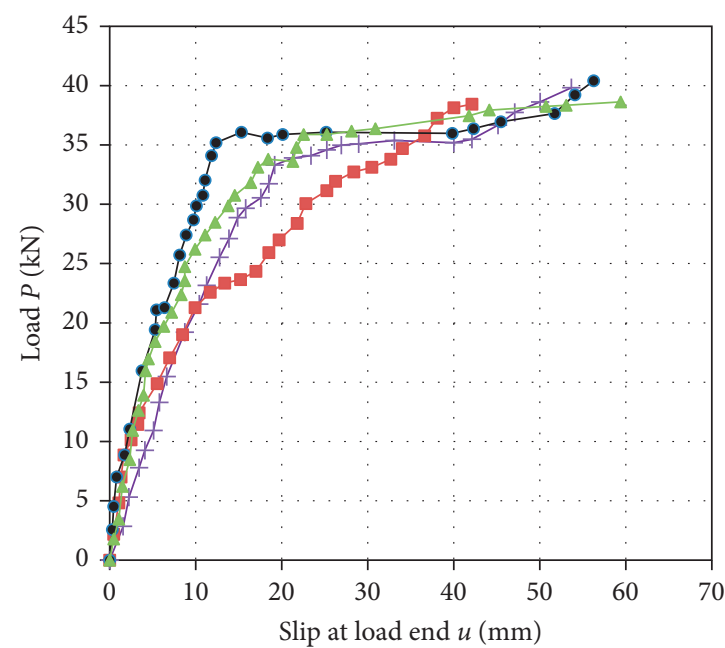

+ CB-L-2000a

$\rightarrow$ CB-L-2000b $\rightarrow$ CB-L-3000a

$\triangle$ CB-L-3000b

(a)

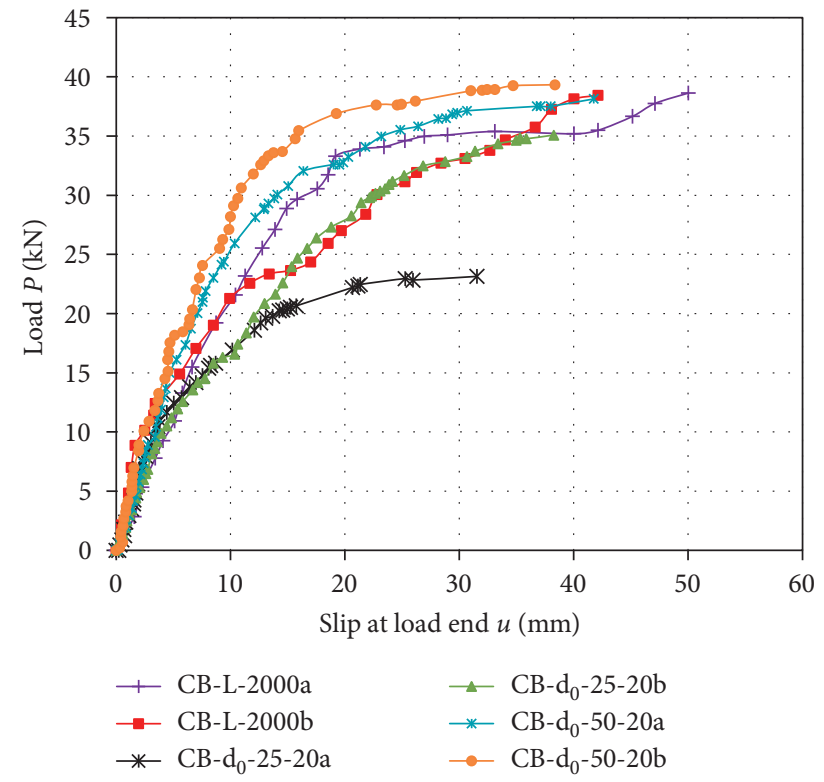

(b)

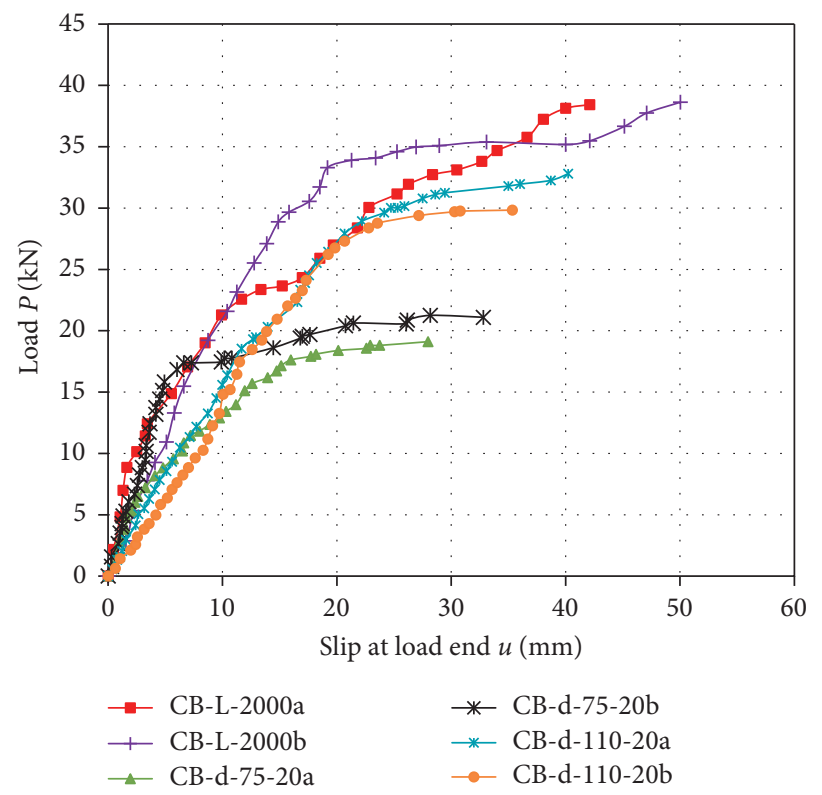

(c)

Figure 13: Load-displacement curve of long bolt specimens ( $L \geq L_{\text {eff }}$ ). (a) Different bolt lengths. (b) Different bolt diameters. (c) Different bolt hole diameters.

longer increases with the length of the anchorage. The existence of the stable section shows that the length of the friction section in the bonded interface is limited and the effect of the complete decoupling of the interface on the anchoring force should be considered.

3.3.2. Bolt Diameter. According to Figures 12(c) and 13(b), no matter whether the anchorage length exceeds the effective value, the maximum pull-out load of the bolt increases with the bolt diameter increasing. The reason is as follows: when the bolt diameter increases, the area with contact with the anchoring agent will increase. As the bond-slip relationship between these two materials is fixed, the total bonding strength will increase.

Comparing Figure 12(c) with Figure 13(b), the loaddisplacement curve corresponding to $L=2 \mathrm{~m}$ is significantly different from that corresponding to $L=1.5 \mathrm{~m}$. In Figure 13(b), the loads on various specimens are finally stabilized within a certain range, but the maximum load varies from the bolt 
diameter. This indicates that the bonding stress in the friction section is not constant and complete decoupling should not be ignored.

3.3.3. Drilling Hole Diameter. According to Figures 12(d) and $13(\mathrm{c})$, the effect of bolt diameter increase on the anchoring force is limited. If the bolt diameter is too large, the anchoring force may decrease. However, if the load is fixed, the displacement of the specimen in a large drilling hole will be larger, and if the bolt diameter is less than a certain value, the anchoring force will decrease greatly. The reason is as follows: if the bolt diameter is fixed, the slurry thickness will be increased with the hole diameter increasing and the shrinkage of anchoring agent subject to capillary action and evaporation will increase, thus resulting in incomplete contact between the bolt and slurry. If slurry is too thin, the shear failure will be prone to happen under large loads, as a result of low shear strength of slurry. This is why the crushed slurry is pulled out together with the bolt in failure of the CB-d-75-20b specimen.

Comparing Figure 12(d) with Figure 13(c), the maximum load will not increase with the slip increasing if the anchorage length $(L)$ is greater than the effective anchorage length $\left(L_{\mathrm{eff}}\right)$.

\subsection{Stress, Strain, and Slip Distribution of Interface in Axial Direction of Bolt}

3.4.1. Parameter Calculation. The stress, strain, and slip distribution of the bonding interface and change with pull-out load increasing are crucial to the performance of the anchorage system. In order to clarify the stress distribution and load transfer of the bamboo bolt-modified slurry interface, the following method is used based on the strain data, to calculate the bonding stress and slip distribution along the bolt.

Assuming that the shear stress between two adjacent strain gauges is equal, the distribution of the interfacial shear stress $\tau_{\max }$ can be obtained according to the maximum shear strain. According to the bolt microsegment equilibrium condition [31-34], the following equation can be obtained:

$$
\tau(x)=E_{p} \cdot r_{p} \cdot \frac{d \varepsilon}{d x}
$$

where $E_{p}$ and $r_{p}$ are the axial stiffness and radius of the bolt, respectively, and $d \varepsilon$ is the strain difference measured by the adjacent strain gauge with a spacing of $d x$.

The above equation can be transformed into

$$
\tau(x)=E_{p} \cdot r_{p} \cdot \frac{\varepsilon_{i+1}-\varepsilon_{i}}{x_{i+1}-x_{i}},
$$

where $E_{p}$ and $r_{p}$ are the axial stiffness and radius of the bolt, respectively; $\varepsilon_{i+1}$ and $\varepsilon_{i}$ are the strain values measured for the $i$ th and $i+1$ th strain gauges, respectively; $x_{i+1}-x_{i}$ is the distance between the adjacent strain gauges; and $\tau(x)$ is the average shear stress between adjacent strain gauges.

Comparing with the stain of the bolt, the strain of modified slurry is negligible. And the relative slip amount between the bamboo bolt and modified slurry can be obtained by the following equation [31-34]:

$$
\varepsilon=\frac{d s}{d x} \Leftrightarrow s=\int_{0}^{L_{b}} \varepsilon d x+s_{0},
$$

where $L_{b}$ is the anchorage length and $s_{0}$ is the amount of slip at the anchoring end. When the anchorage length is enough, it is believed that the anchoring end is fixed, that is, $s_{0}=0$. The relative slip can be solved by the Simpson rule:

$$
s(x)=s\left(x_{i+1}\right)-\frac{\left(\varepsilon_{i+1}-\varepsilon_{i}\right)}{\left(x_{i+1}-x_{i}\right)} \cdot \frac{\left(x_{i+1}-x\right)^{2}}{2}+\varepsilon_{i+1} \cdot\left(x_{i+1}-x_{i}\right) .
$$

3.4.2. Stress, Strain, and Slip Distribution of the Bonding Interface in Axial Direction of Bolt. In order to compare the stress states of the bonding interface in different stages of the trilinear bond-slip model, the bond-slip process is divided into four points, that is, A, B, C, and D, according to the loading end slip of the bolt. The point A represents the prepeak stage, in which the shear stress of the bonding interface does not exceed the maximum shear stress $\left(\tau_{\max }\right)$; the point $\mathrm{B}$ represents the maximum bonding stress; and the points $\mathrm{C}$ and $\mathrm{D}$ are located in the softening or friction section of the bond-slip model. The slips $(s)$ of the points A, B, C, and $\mathrm{D}$ of the short $\left(L<L_{\mathrm{eff}}\right)$ bolt specimen are, respectively, $1.19 \mathrm{~mm}, 3.75 \mathrm{~mm}, 10.11 \mathrm{~mm}$, and $18.97 \mathrm{~mm}$; and the slips $(s)$ of the points A, B, C, and D of the long ( $\left.L \geq L_{\mathrm{eff}}\right)$ bolt specimen are, respectively, $1.97 \mathrm{~mm}, 4.12 \mathrm{~mm}, 15.90 \mathrm{~mm}$, and $22.97 \mathrm{~mm}$.

Figure 14 shows the stress, strain, and slip distribution of the bonding interface in the axial direction of the short bolt $\left(L<L_{\text {eff }}\right)$. As the bolt is relatively short, the slip of the point D is not achieved in the test, and the slip of the interface near the anchoring end is very small in the early loading period. When the load is increased, the slip of the interface near the anchoring end will increase gradually. This indicates that the bonding stress is gradually transferred from the loading end to the anchoring end while the load is increased. As can be seen from the stress distribution diagram, the bonding strength of the interface near the anchoring end of the short bolt is not fully utilized.

Figure 15 shows the stress, strain, and slip distribution of the bonding interface in the axial direction of the long bolt ( $\left.L \geq L_{\text {eff }}\right)$. The slip of the long bolt ( $\left.L \geq L_{\text {eff }}\right)$ specimen is greater than that of the short bolt $\left(L<L_{\text {eff }}\right)$ specimen. The interface stress and strain distribution corresponding to the long bolt is also different from that corresponding to the short bolt. According to the bonding stress diagram, if a small load is applied, the stress on the interface at the loading end will reach the peak value. If the load is increased, the stress peak will be transferred to the anchoring end and the corresponding strain increase will be gradually stabilized at the maximum shear strain. This indicates that the bonding interface is completely decoupled, and the shear stress is approximated to zero. According to the 

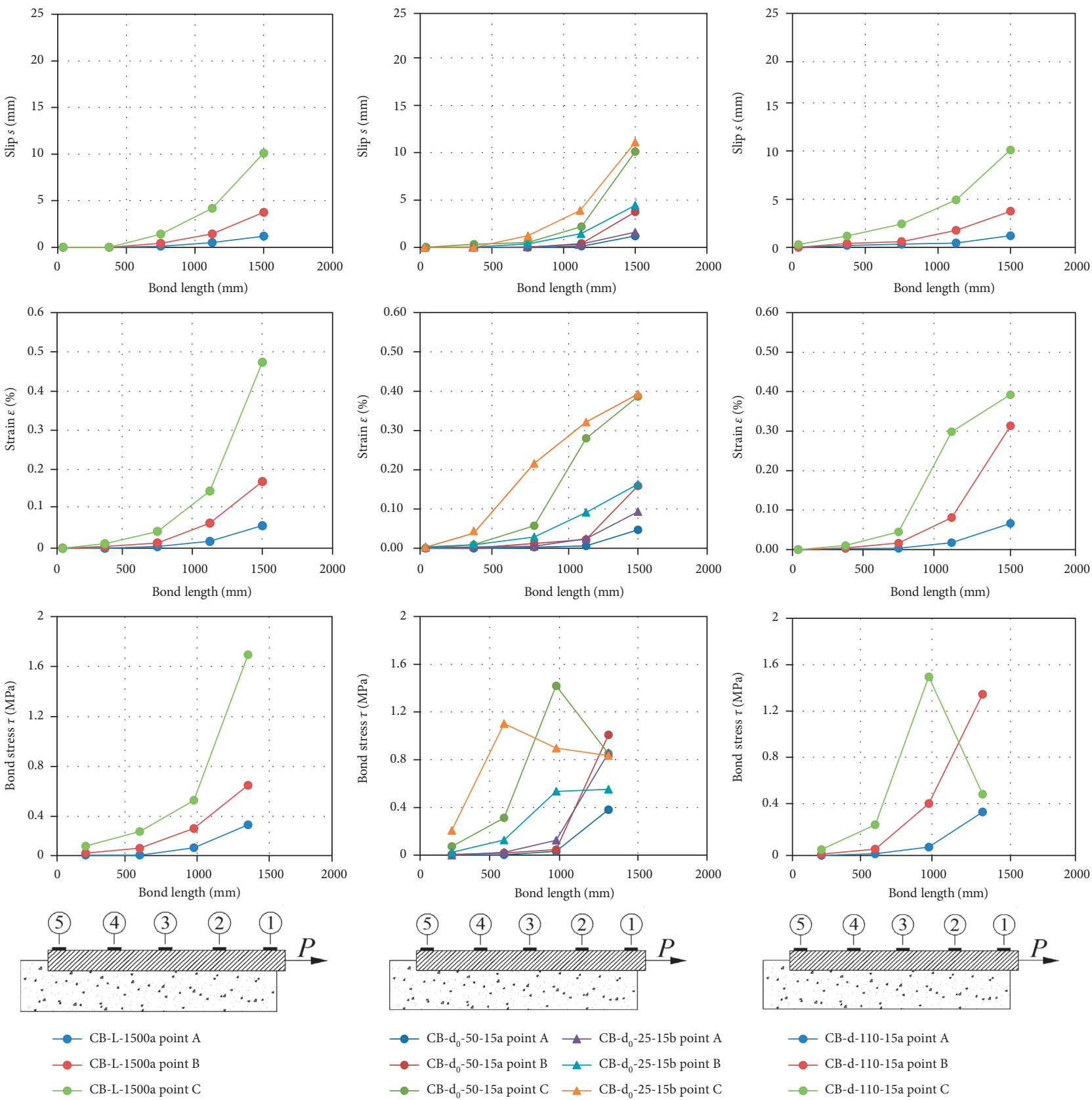

FIgURE 14: Stress, strain, and slip distribution of the bonding interface in the axial direction of the short bolt $\left(L<L_{\text {eff }}\right)$.

strain distribution of various specimens at the point $\mathrm{D}$, the stable section of CB-d-110-20b specimen is the longest and close to the whole anchorage length. This indicates that the most of the bonding interface is in the complete decoupling stage and the anchorage system is close to failure.

3.4.3. Ultimate Anchoring Performance. The results of pullout experiment of the interface between bamboo bolt and modified slurry are shown in Table 8 . It can be seen that if the anchorage length is increased, the maximum load transferred to the bolt will increase gradually. The maximum strain value of the bonding interface measured in all samples is about $0.163 \% \sim 0.617 \%$, which is much smaller than that of the fracture strain of bamboo (about 2.68\%). This indicates that the bond strength of this kind of anchoring interface is limited with only about $6 \% \sim 23 \%$ of the strength of bamboo material being exerted. The anchoring force can be further increased by ribbing or reinforcement.

It should also be noted that the maximum load, maximum shear stress, and slip are significantly affected by the bolt diameter and drilling hole diameter. If the drilling hole diameter is $75 \mathrm{~mm}$, the anchorage strength of each specimen will decline greatly, the maximum slip will be approximate to the ultimate slip, and the slurry will be subjected to local crushing in the case of failure. 

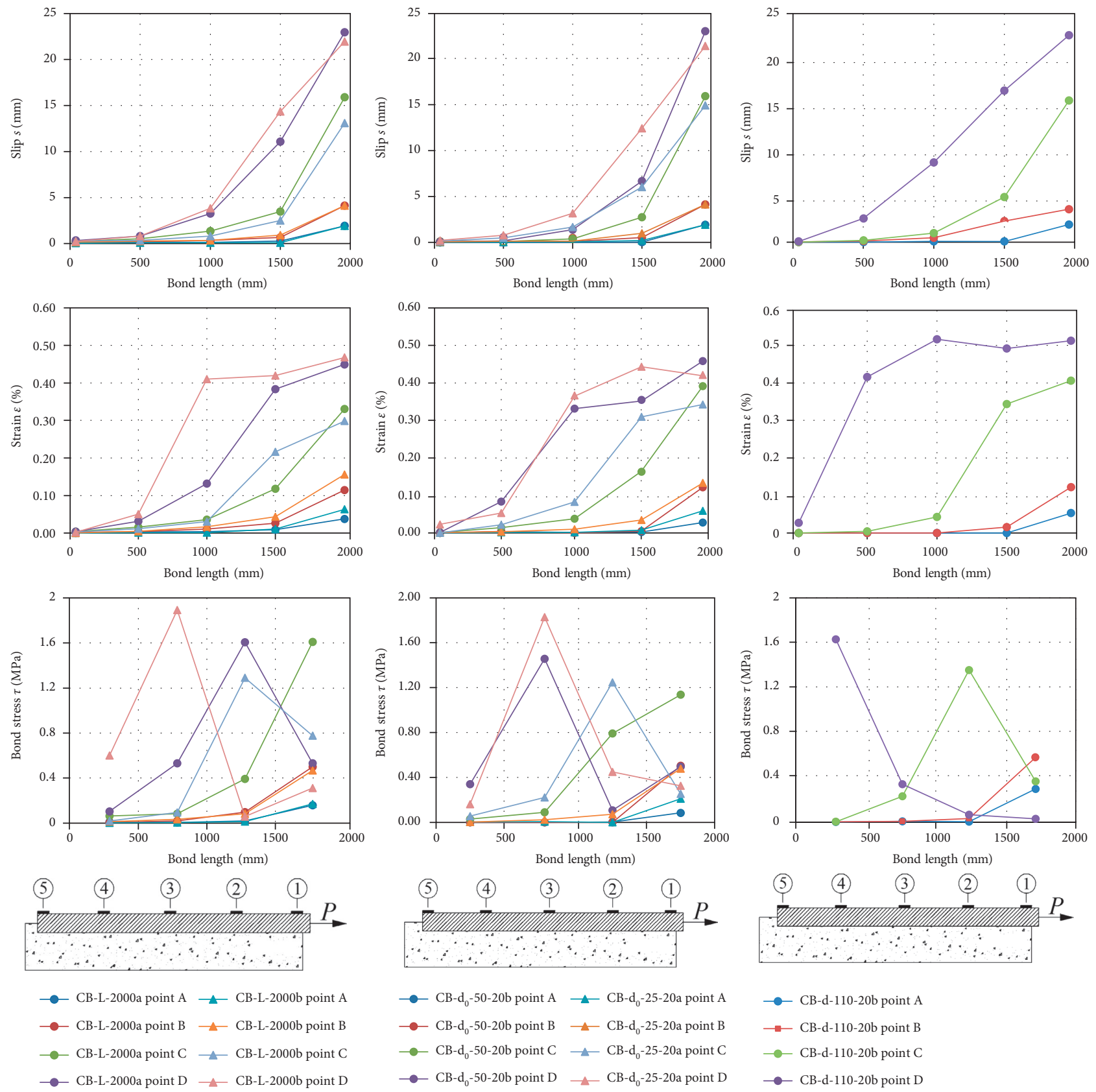

FIGURE 15: Stress, strain, and slip distribution of the bonding interface in the axial direction of the long bolt ( $L \geq L_{\text {eff }}$ ).

\section{Bamboo-Modified Slurry Interface Bond-Slip Model}

4.1. Interface Microsegment Strain-Slip Relationship. According to the load-displacement curve in Figures 14 and 15, it can be seen that the bond interface reaches the ultimate strength only when the anchoring length is sufficient $\left(L \geq L_{\text {eff }}\right)$, then the interface near the anchoring end is mobilized to resist the pullout load, and the complete interface bond-slip model is obtained. Therefore, only the interface strain-slip distribution data of the long bolt ( $L \geq L_{\text {eff }}$ ) specimens (CBL-2000a, CB-L-2000b, CB-L-3000a, and CB-L-3000b) are selected.
According to the strain data measured in the test, the slip amount of each measuring point can be obtained according to (2) and (3), and the strain-slip curve of the microsection bond interface of the long anchor sample is shown in Figure 16.

It can be seen from Figure 16 that the strain-slip distribution trend of the bolt samples is similar, both showing a certain nonlinear variation trend. When the relative slip of the interface is small, the strain-slip data at any position of the bond interface are linearly distributed. With the increase of the amount of slip, the shear strain enters the nonlinear change stage gradually and the interface strain growth rate is slowed down compared with the initial stage, indicating that 
TABLE 8: The results of the pull-out experiment of the interface between bamboo bolt and modified slurry.

\begin{tabular}{|c|c|c|c|c|c|c|}
\hline Specimen & $\begin{array}{c}\text { Anchoring length } \\
L_{b}(\mathrm{~mm})\end{array}$ & $\begin{array}{c}\text { Maximum load } \\
F_{\max }(\mathrm{kN})\end{array}$ & $\begin{array}{c}\text { Maximum strain } \\
\varepsilon_{\max }(\%)\end{array}$ & $\begin{array}{c}\text { Maximum stress } \\
\tau_{\max }(\mathrm{MPa})\end{array}$ & $\begin{array}{l}\text { Maximum slip } \\
s_{\max }(\mathrm{mm})\end{array}$ & $\begin{array}{l}\text { Ultimate slip }^{\mathrm{b}} s_{\text {ult }} \\
(\mathrm{mm})\end{array}$ \\
\hline $\begin{array}{l}\text { CB-L- } \\
800 \mathrm{a}\end{array}$ & 800 & 3.75 & 0.384 & 0.751 & - & - \\
\hline $\begin{array}{l}\text { CB-L- } \\
800 \mathrm{~b}\end{array}$ & 800 & 19.39 & 0.163 & 0.648 & 10.87 & 26.17 \\
\hline $\begin{array}{l}\text { CB-L- } \\
1200 a\end{array}$ & 1200 & 28.36 & 0.551 & 1.231 & 9.84 & 29.72 \\
\hline $\begin{array}{l}\text { CB-L- } \\
1200 b\end{array}$ & 1200 & 25.22 & 0.410 & 1.659 & 12.36 & 24.05 \\
\hline $\begin{array}{l}\text { CB-L- } \\
1500 \mathrm{a}\end{array}$ & 1500 & 35.72 & 0.481 & 1.694 & 14.57 & 27.33 \\
\hline $\begin{array}{l}\text { CB-L- } \\
1500 b\end{array}$ & 1500 & 34.47 & 0.50 & 1.203 & 16.27 & 23.27 \\
\hline $\begin{array}{l}\text { CB-L- } \\
2000 a\end{array}$ & 2000 & 39.82 & 0.449 & 1.737 & 23.23 & 53.68 \\
\hline $\begin{array}{l}\text { CB-L- } \\
2000 b\end{array}$ & 2000 & 38.44 & 0.467 & 1.892 & 29.00 & 59.38 \\
\hline $\begin{array}{l}\text { CB-L- } \\
3000 a\end{array}$ & 3000 & 40.50 & 0.60 & 2.31 & 17.12 & 55.16 \\
\hline $\begin{array}{l}\text { CB-L- } \\
3000 b\end{array}$ & 3000 & 38.63 & 0.521 & 1.652 & 20.91 & 60.89 \\
\hline $\begin{array}{l}\text { CB- } \mathrm{d}_{0^{-}} \\
25-15 \mathrm{a}\end{array}$ & 1500 & 31.08 & 0.346 & 1.306 & 21.97 & 23.71 \\
\hline $\begin{array}{l}\text { CB- } d_{0^{-}} \\
25-15 b\end{array}$ & 1500 & 31.54 & 0.393 & 1.102 & 17.24 & 23.27 \\
\hline $\begin{array}{l}\text { CB- } \mathrm{d}_{0^{-}} \\
25-20 \mathrm{a}\end{array}$ & 2000 & 23.14 & 0.451 & 1.829 & 32.26 & 39.54 \\
\hline $\begin{array}{l}\text { CB- } \mathrm{d}_{0^{-}} \\
25-20 \mathrm{~b}\end{array}$ & 2000 & 35.08 & 0.293 & 0.977 & 36.57 & 46.47 \\
\hline $\begin{array}{l}\text { CB- } \mathrm{d}_{0^{-}} \\
50-15 \mathrm{a}\end{array}$ & 1500 & 41.03 & 0.386 & 1.418 & 12.83 & 34.78 \\
\hline $\begin{array}{l}\text { CB- } \mathrm{d}_{0^{-}} \\
50-15 \mathrm{~b}\end{array}$ & 1500 & 33.03 & 0.617 & 2.011 & 16.99 & 23.66 \\
\hline $\begin{array}{l}\text { CB- } \mathrm{d}_{0^{-}} \\
50-20 \mathrm{a}\end{array}$ & 2000 & 38.13 & 0.462 & 1.457 & 23.08 & 41.74 \\
\hline $\begin{array}{l}\text { CB- } \mathrm{d}_{0^{-}} \\
50-20 \mathrm{~b}\end{array}$ & 2000 & 39.33 & 0.485 & 1.766 & 24.98 & 38.35 \\
\hline $\begin{array}{l}\text { CB-d-75- } \\
15 a\end{array}$ & 1500 & 16.14 & 0.331 & 0.783 & 9.92 & 10.16 \\
\hline $\begin{array}{l}\text { CB-d-75- } \\
15 b\end{array}$ & 1500 & 14.63 & 0.293 & 1.114 & 12.93 & 14.99 \\
\hline $\begin{array}{l}\text { CB-d-75- } \\
20 a\end{array}$ & 2000 & 19.11 & 0.49 & 1.258 & 25.96 & 30.21 \\
\hline $\begin{array}{l}\text { CB-d-75- } \\
20 \mathrm{~b}\end{array}$ & 2000 & 21.09 & 0.259 & 0.624 & 29.81 & 28.63 \\
\hline $\begin{array}{l}\text { CB-d- } \\
110-15 a\end{array}$ & 1500 & 33.13 & 0.384 & 1.494 & 16.33 & 41.11 \\
\hline $\begin{array}{l}\text { CB-d- } \\
110-15 b\end{array}$ & 1500 & 35.19 & 0.462 & 1.789 & 25.69 & 47.68 \\
\hline $\begin{array}{l}\text { CB-d- } \\
110-20 a\end{array}$ & 2000 & 32.81 & 0.441 & 1.233 & 31.99 & 60.22 \\
\hline $\begin{array}{l}\text { CB-d- } \\
110-20 b\end{array}$ & 2000 & 29.83 & 0.510 & 1.627 & 30.78 & 53.78 \\
\hline
\end{tabular}

${ }^{\mathrm{a}_{\mathrm{max}}}$ and ${ }^{\mathrm{b}} s_{\mathrm{ult}}$ are the maximum slip and ultimate slip that are the amount of slip corresponding to the maximum load and the failure of the anchor system, respectively. 


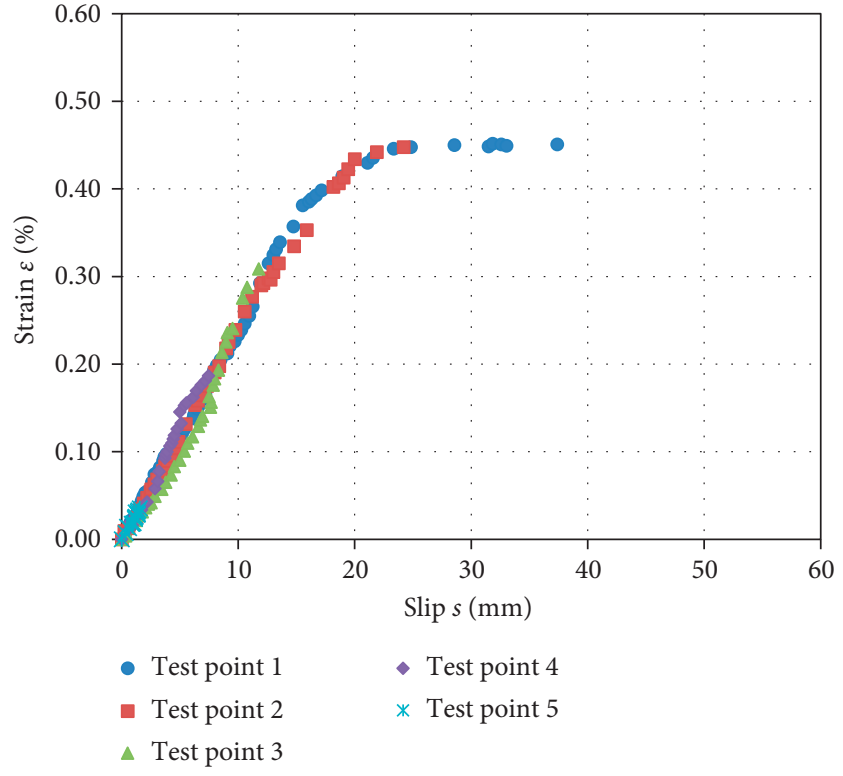

(a)

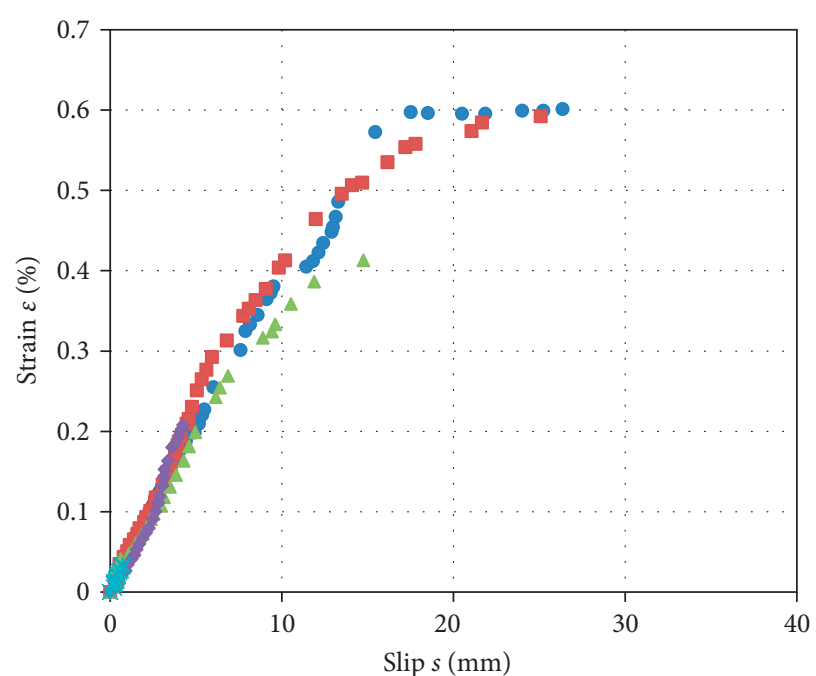

- Test point 1

- Test point 2

^ Test point 3

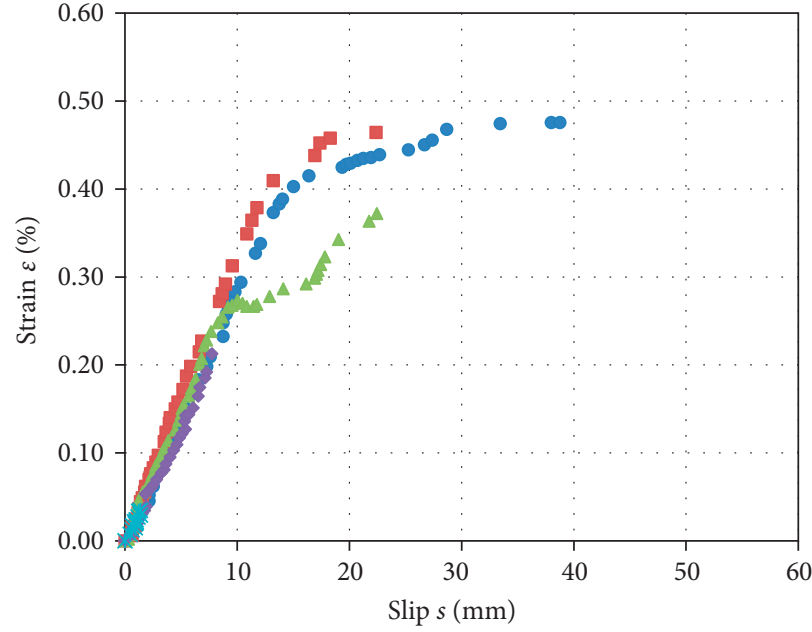

- Test point 1 - Test point 4

- Test point $2 \quad *$ Test point 5

$\triangle$ Test point 3

(b)

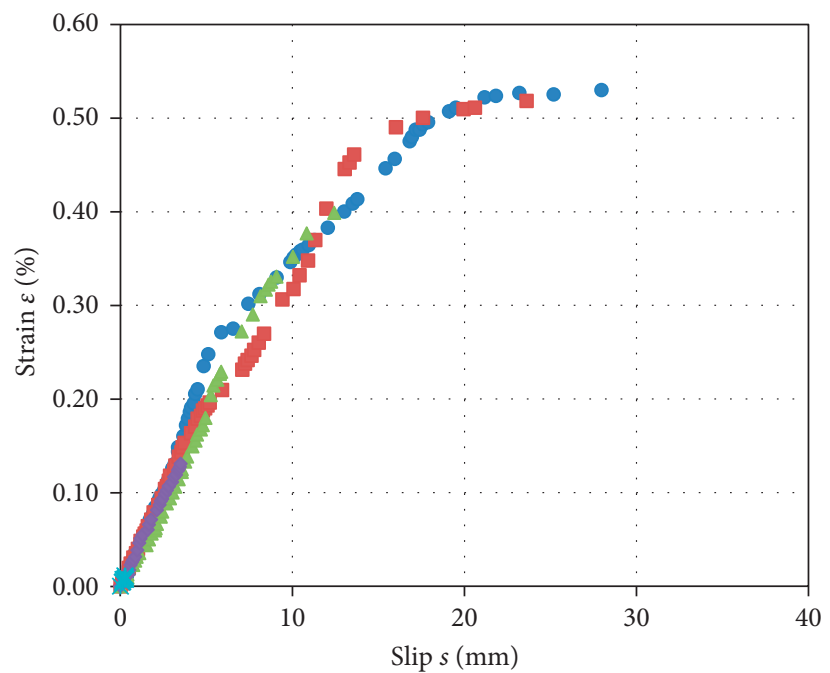

- Test point 1

- Test point 4

- Test point 2

* Test point 5

(c)

(d)

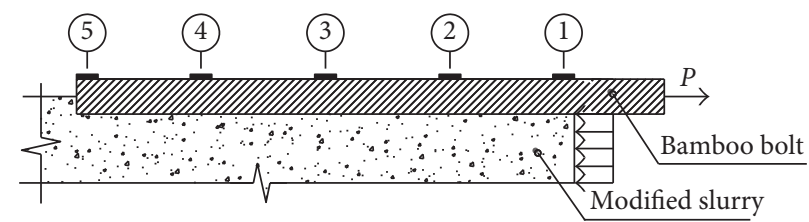

(e)

FIGURE 16: Microsection strain-slip curve of bamboo bolt-modified slurry interface $\left(L_{b} \geq L_{\text {eff }}\right.$ ). (a) CB-L-2000a. (b) CB-L-2000b. (c) CB-L3000a. (d) CB-L-3000b. (e) Strain gauge distribution on bamboo bolt surface. 
the interface has certain flexibility characteristics, which will directly affect the final mechanical properties of the interface. Finally, when the relative slip reaches a certain value, the interface strain reaches the peak and does not change with the increase of the slip amount until the bond interface is destroyed. At this time, the interface strain-slip distribution is close to the horizontal, indicating that the bond interface begins to appear completely decoupling. The biggest difference between this type of the interface model and the trilinear bond-slip model is embedded in the existence of the fully decoupled section. Ignoring the complete decoupling phenomenon will overestimate the bearing capacity of the anchoring system. The above three-stage behavior only can be measured on the interface near the loading end, and the interface near the anchoring end is always elastic, indicating that the shear stress of the interface also has a negative exponential distribution similar to that of a metal bolt and cement mortar interface.

4.2. Bond-Slip Curves of Bamboo Bolt-Modified Slurry Interface. The foregoing results show that the failure of the anchorage system is mainly caused by the pullout of the anchor bolt from the modified slurry under pull-out load. Therefore, the mechanical properties of interface between bamboo bolt and modified slurry are the key factor to controlling the ultimate pull-out performance of the anchoring system. Researchers have proposed several bondslip models to simulate the mechanical behavior of the anchorage interface, which can be roughly divided into nonlinear model and sectional linear model, but whether the mechanical behavior of bamboo bolt-modified slurry interface conforms to the existing model is not clear.

Figure 17 is the bond-slip curve of bamboo bolt-modified slurry interface ( $\tau$-s curve). In order to guarantee that more stages of the curve can be identified, only the test data near the loading end are listed (distribution of test points can be referred to Figure 16(e)).

It can be known from the bond-slip curve of test point intervals that when the slippage is small, the deformation of bolt and anchoring agent is coordinated, and the pull-out load is mainly borne by the chemical bonding force and the mechanical interlocking force of the interface, and the curve is approximately linear. As the slippage of interface increases, the shear stress reaches its peak value, and then the softening stage begins. At the softening stage, the shear stress decreases rapidly with the increase of slippage, the chemical bonding force disappears, and the pull-out load is mainly borne by the friction force and the mechanical interlocking force. As the slippage continues to increase, the interfacial shear stress decreases to zero near the loading end and the residual friction effect is very limited at this time.

Comparing the slip curves of different measuring point interval, it can be known that the slope of the curve is similar and the initial stiffness of each measuring point interval is the same when the slippage value is small. The peak value of the shear stress of the test point 2-3 is greater than that of the test point 1-2; this may be due to the loosening of soil near the loading end, which leads to the hoop constraint strength of soil to anchor bolt reduction.

Figure 18 shows the fitting results of the bond-slip curve and several kinds of existing bond-slip models of bamboo bolt-modified slurry interface. As can be seen from Figures 18(a) and 18(c), the bond-slip curve obtained by pull-out test fits well with the bond-slip model when the slippage is less than $20 \mathrm{~mm}$. However, when the slippage is large, the interfacial shear stress of the two models remains as the residual friction stress, and the interfacial shear stress is overestimated. The nonlinear model in Figure 18(b) fits well with the bondslip curve obtained by pull-out test; the model considered that the interfacial shear stress is zero when the slippage is large, but if the influence of the friction stage is ignored, the bond strength of the interface will be underestimated. The bond-slip model in Figure 18(d) does not fit well with the test curve when the slippage value is greater than $7 \mathrm{~mm}$.

It can be known from the above analysis that none of the existing bond-slip model can well simulate the bond-slip behavior of bamboo bolt-modified slurry interface, but as long as the friction segment on the model curve in Figure 18(a) or Figure 18(c) is modified to give sufficient consideration to the complete decoupling phenomenon of the interface under large slippage, these two models can well simulate the bondslip behavior of bamboo bolt-modified slurry interface.

\subsection{Correspondence between Strain-Slip Curve and Bond-Slip} Model. Considering the convenience of the linear model in analytic calculation, this section will identify the complete decoupling phenomenon of anchorage interface according to the corresponding relationship between the strain-slip curve and the trilinear bond-slip model. The corresponding relationship between the strain-slip curve and the bond-slip model is shown in Figure 19. Functions (5-10) and (12-14) are taken from Biscaia et al. [35].

According to the force balance of the bamboo bolt, the bond-slip model of the interface between the bolt and the modified slurry can be determined. It is assumed that the linear segments of the strain-slip curve have the following relationship:

$$
\varepsilon(s)=\frac{\varepsilon_{1}}{s_{1}} \cdot s,
$$

where $\varepsilon(s)$ and $s$ are the interface shear strain and its corresponding slip, respectively; $\varepsilon_{1}$ is the maximum strain in the linear phase of the strain-slip curve; and $s_{1}$ is the slip amount corresponding to $\varepsilon_{1}$.

According to the balance conditions of bolt microsegments $[36,37]$, the following equation is applicable:

$$
\tau(x)=E_{p} \cdot r_{p} \cdot \frac{d \varepsilon}{d s} \cdot \frac{d s}{d x},
$$

where $E_{p}$ and $r_{p}$ are the axial stiffness and radius of the bolt, respectively; $d \varepsilon$ is the strain difference measured by the adjacent strain gauge with a spacing of $d x$; and

$$
\varepsilon=\frac{d s}{d x} \text {. }
$$




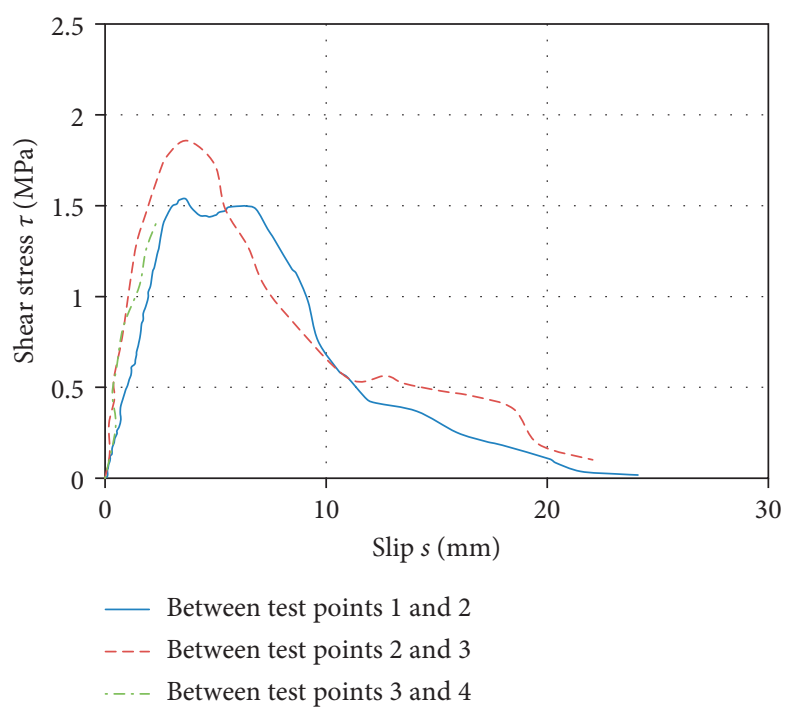

(a)

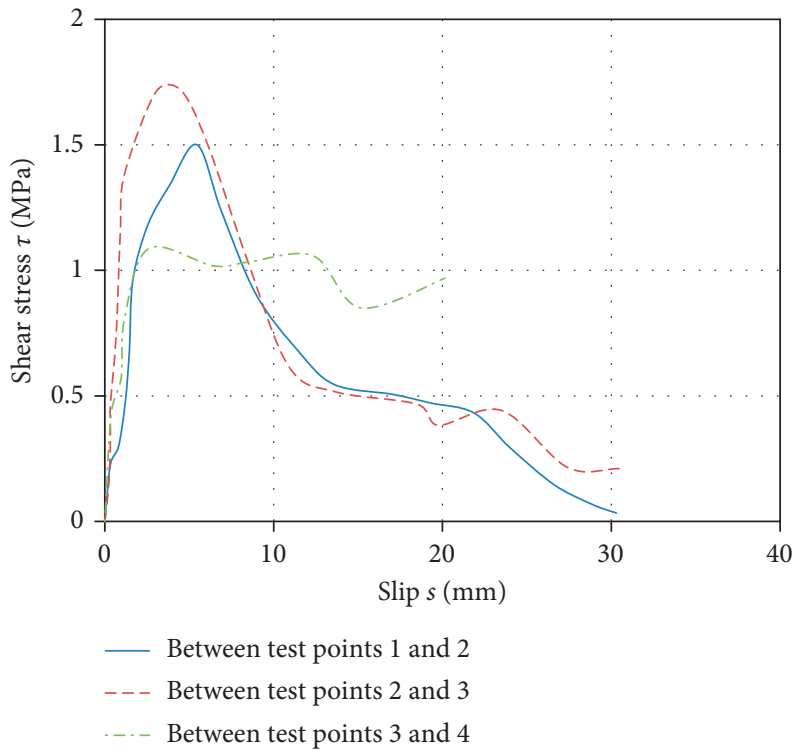

(c)

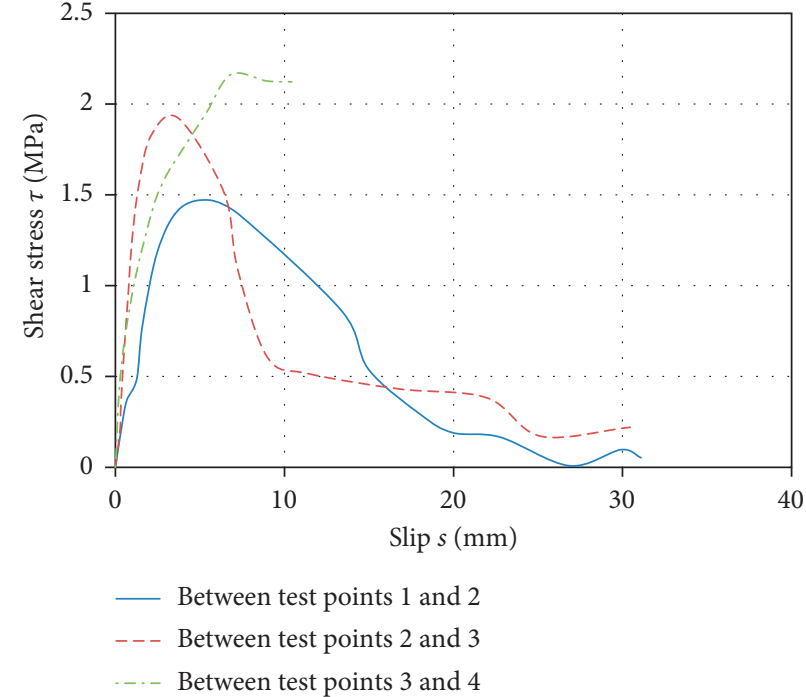

(b)

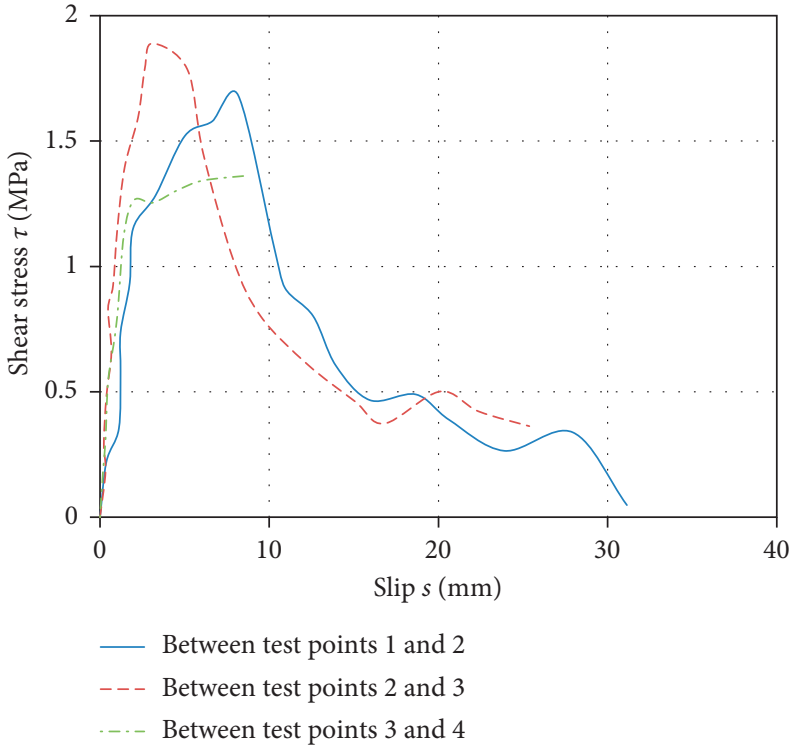

(d)

Figure 17: Bond-slip curve of bamboo bolt-modified slurry interface ( $\tau$-s curve). (a) CB-L-2000a. (b) CB-L-2000b. (c) CB-L-3000a. (d) CBL-3000b.

Taking (5)-(7) into consideration, the elastic segment of the bond-slip model can be expressed as

$$
\tau(s)=E_{p} \cdot r_{p} \cdot s \cdot\left(\frac{\varepsilon_{1}}{s_{1}}\right)^{2}
$$

where $\tau(s)$ is the shear stress corresponding to the slip of $s$.

As can be seen in Figure 19, when the relative length of the bolt microslip is between 0 and $s_{1}$, the bond-slip curve is linear. Therefore, with reference to the correspondence of the two curves, in case of $s=s_{1}$, the maximum value $\tau_{1}$ will be reached by the interfacial shear stress. According to (5), the following equation can be obtained:

$$
\tau_{1}\left(s=s_{1}\right)=E_{p} \cdot r_{p} \cdot \frac{\varepsilon_{1}^{2}}{s_{1}} .
$$

The linear softening section (Figure 19, $s_{1} \sim s_{2}$ section) of the bond-slip model can be determined by

$$
\tau(s)=\frac{\tau_{2}-\tau_{1}}{s_{2}-s_{1}} \cdot s+\frac{\tau_{1} \cdot s_{2}-\tau_{2} \cdot s_{1}}{s_{2}-s_{1}},
$$

where $s_{2}$ is the amount of slip corresponding to the end of the nonlinear segment (trigonometric function). Substituting (9) into (10), the linear softening segment of interface bond-slip model can be expressed as 


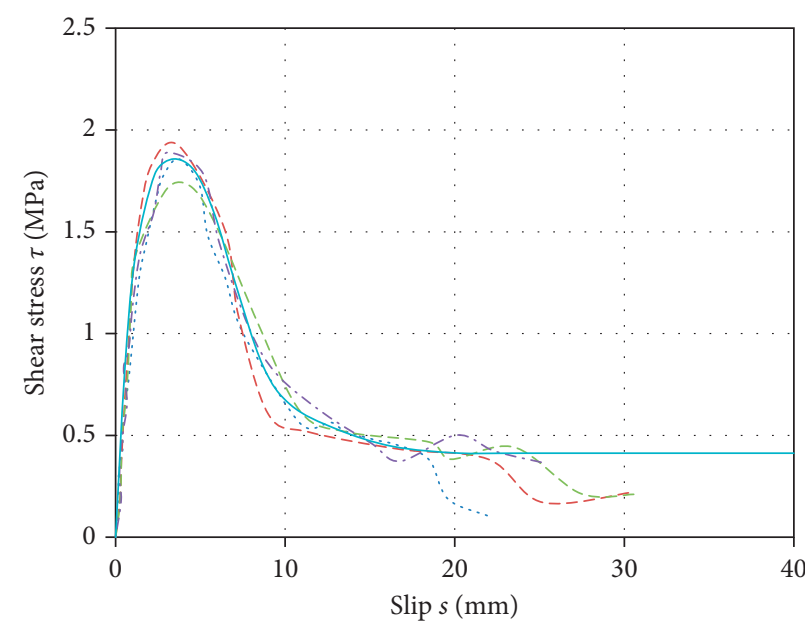

CB-L-2000a test points 2-3

-- - CB-L-2000b test points 2-3

- - CB-L-3000a test points 2-3

...- CB-L-3000b test points 2-3

_ Nonlinear model (D. Y. Gao)

(a)

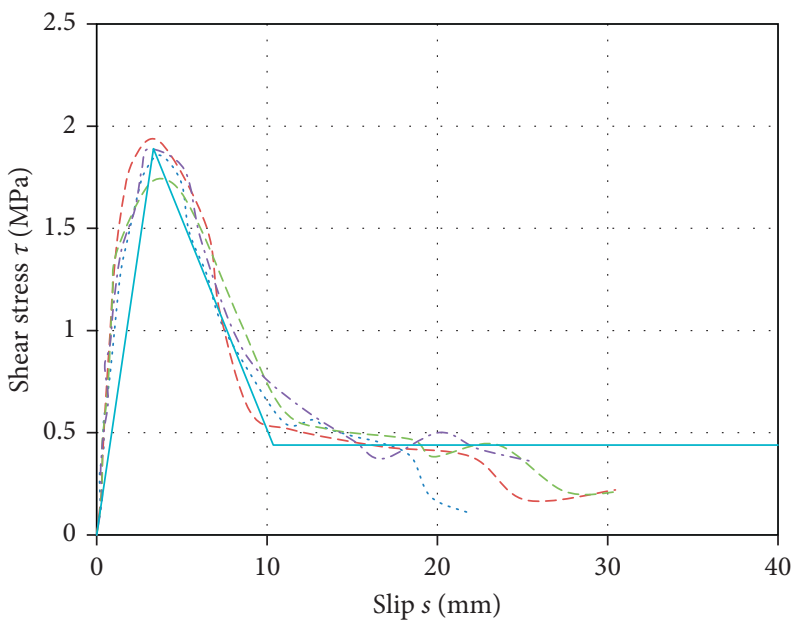

CB-L-2000a test points 2-3

- - CB-L-2000b test points 2-3

- - CB-L-3000a test points 2-3

... CB-L-3000b test points 2-3

_ Trilinear model

(c)

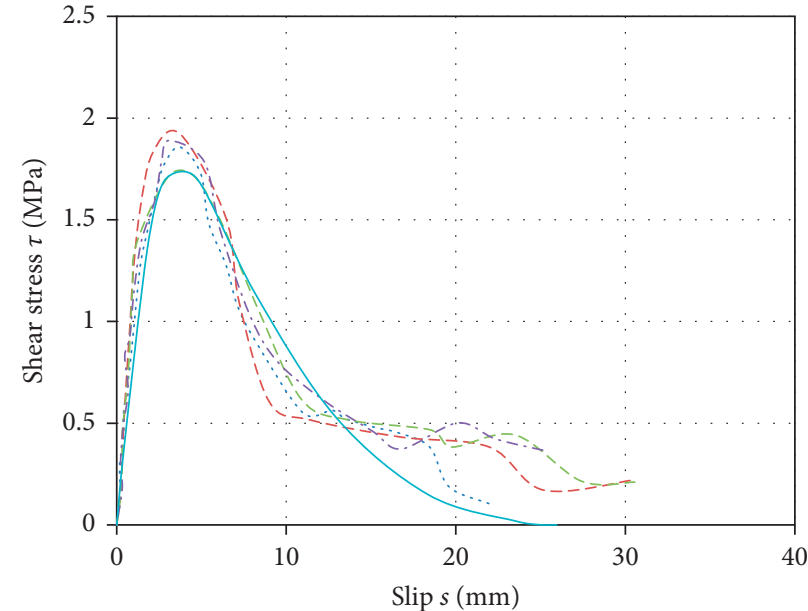

CB-L-2000a test points 2-3

- - CB-L-2000b test points 2-3

- - CB-L-3000a test points 2-3

-.- CB-L-3000b test points 2-3

_ Nonlinear model (S. Ma)

(b)

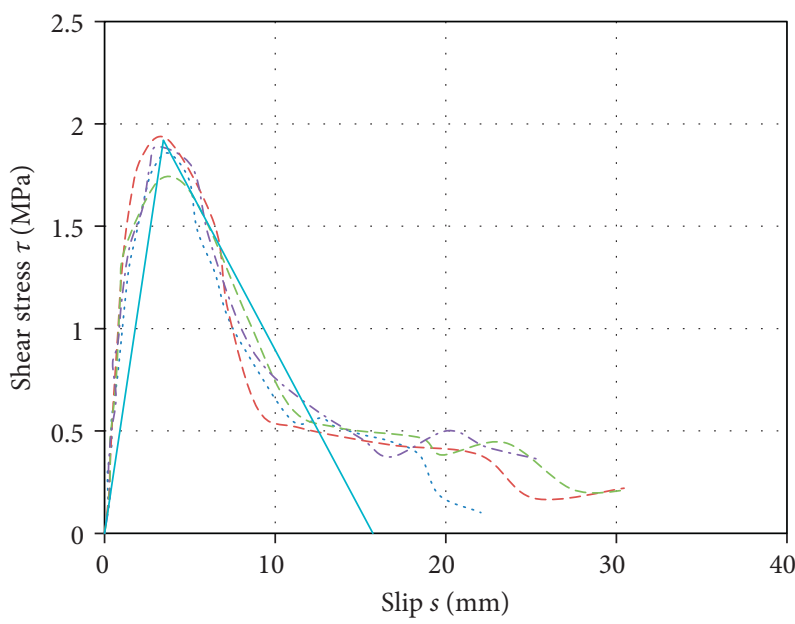

... CB-L-2000a test points 2-3

- - CB-L-2000b test points 2-3

- $C B-L-3000$ a test points 2-3

.... CB-L-3000b test points 2-3

_ Bilinear model

FIGURE 18: Fitting results of the bond-slip curve and bond-slip model of bamboo bolt-modified slurry interface. (a) Fitting results of the nonlinear model (D. Y. Gao). (b) Fitting results of the nonlinear model (S. Ma). (c) Fitting results of the trilinear model. (d) Fitting results of the bilinear model.

$$
\tau(s)=\frac{\tau_{2} \cdot s_{1} \cdot\left(1-s_{1}\right)+E_{p} \cdot r_{p} \cdot \varepsilon_{1}^{2}\left(s_{2}-s\right)}{s_{1} \cdot\left(s_{2}-s_{1}\right)} .
$$

As shown in Figure 19(a), the strain-slip curve corresponding to the linear softening section of the bond-slip model is nonlinear. According to the Biscaia et al.'s research results $[17,35]$, the relationship between the bolted microsegment strain and the relative slip can be expressed by the trigonometric function:

$$
\varepsilon=\alpha \cdot\left(s_{2}-s_{1}\right) \cdot \sin \left[\arccos \left(\frac{s_{2}-s_{1}-s}{s_{2}-s_{1}}\right)\right],
$$




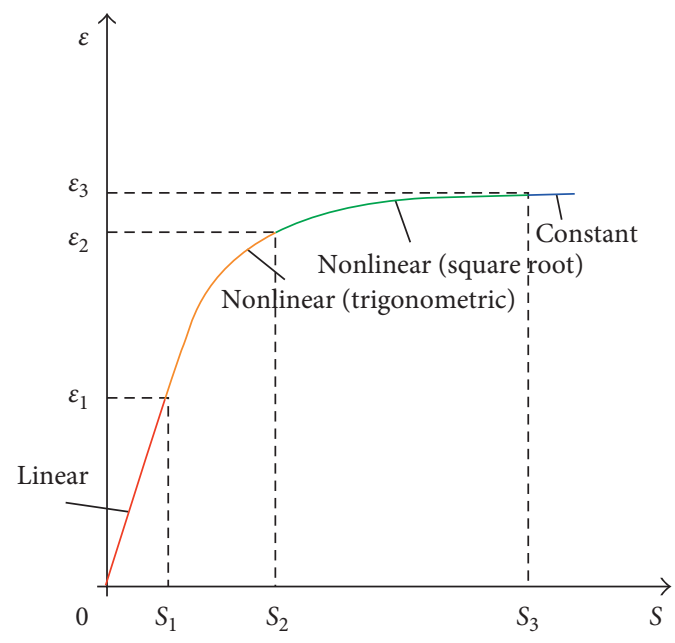

(a)

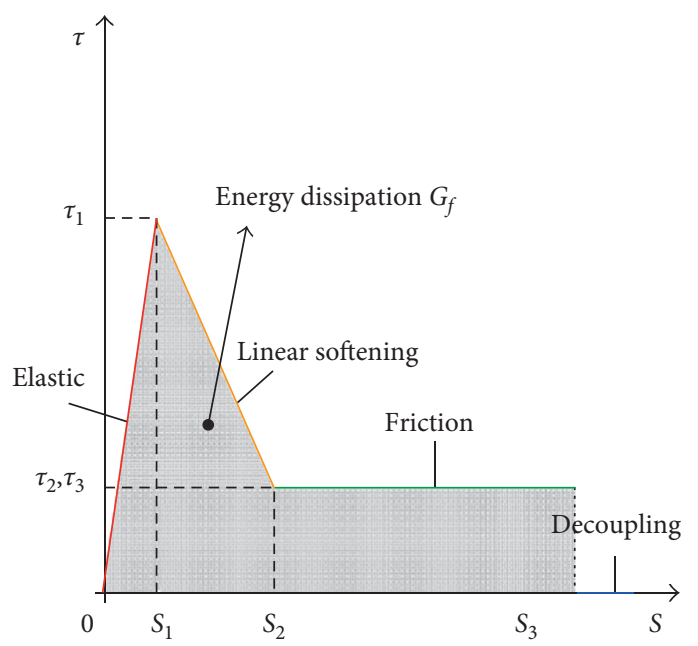

(b)

FIGURE 19: The corresponding relationship between the strain-slip curve and the interfacial bond-slip model. The strain-slip curve of the linear segment is corresponding to the interface bond-slip model of the elastic section. The nonlinear segment (trigonometric function) is corresponding to the linear softening section. The nonlinear segment (square root) is corresponding to the friction section, and the constant segment is corresponding to the fully decoupled section. (a) The strain-slip curve at loading end. (b) The interfacial bond-slip model. This figure is reproduced with permission from the American Society of Civil Engineers (all rights reserved) [35].

TABLE 9: The parameters of bamboo-modified slurry interface bond-slip model (mean).

\begin{tabular}{lcccccc}
\hline Interface & $s_{1}(\mathrm{~mm})$ & $s_{2}(\mathrm{~mm})$ & $s_{3}(\mathrm{~mm})$ & $\tau_{1}(\mathrm{MPa})$ & $\tau_{2}(\mathrm{MPa})$ & $G_{f}(\mathrm{~N} / \mathrm{mm})$ \\
\hline Bamboo bolt-modified slurry & 3.34 & 10.73 & 22.56 & 1.89 & 0.44 & 16.97 \\
\hline
\end{tabular}

where

$$
\alpha=\sqrt{\frac{\tau_{1}-\tau_{2}}{E_{P} \cdot r_{p} \cdot\left(s_{2}-s_{1}\right)}}
$$

The shear stress of the third stage (Figure 19, $s_{2} \sim s_{3}$ section) of the interface bond-slip model is constant, and the corresponding strain-slip curve can be expressed by the square root $[17,35]$ :

$$
\varepsilon=\sqrt{\frac{2 \tau_{2} \cdot\left(s-s_{2}\right)}{E_{p} \cdot r_{p}}}
$$

Substituting (14) into (6), the shear stress $\tau(s)$ can be obtained; its constant value is equal to $\tau_{2}$.

The total energy $G_{f}$ dissipated during the whole process of the bond-slip can be determined by the area formed by the lines of the bond-slip model and the coordinate axis:

$$
G_{f}=\int_{0}^{s_{2}} \tau(s) d s+\tau_{2} \cdot\left(s_{3}-s_{2}\right)
$$

Taking (8) and (11) into consideration, (15) can be transformed into

$$
\begin{aligned}
G_{f}= & \int_{0}^{s_{2}} E_{p} \cdot r_{p} \cdot s \cdot\left(\frac{\varepsilon_{1}}{s_{1}}\right)^{2} d s \\
& +\int_{s_{1}}^{s_{2}} \frac{\tau_{2} \cdot s_{1} \cdot\left(1-s_{1}\right)+E_{p} \cdot r_{p} \cdot \varepsilon_{1}^{2} \cdot\left(s_{2}-s\right)}{s_{1} \cdot\left(s_{2}-s_{1}\right)} d s \\
& +\tau_{2} \cdot\left(s_{3}-s_{2}\right) .
\end{aligned}
$$

Considering (9) and solving (16), the total energy released by the whole process of the bond-slip is

$$
G_{f}=\frac{\tau_{1} \cdot s_{1}}{2}+\frac{\left(\tau_{1}+\tau_{2}\right)\left(s_{2}-s_{1}\right)}{2}+\tau_{2} \cdot\left(s_{3}-s_{2}\right) .
$$

When the effective bond length is determined, the maximum anchorage force that a single bolt can provide can be quickly obtained; the calculation method will be described in detail in subsequent articles.

According to the strain-slip curve, the interface strain reaches the peak from the slip $s_{3}$ and will not continue to increase with the slip increasing. Therefore, if the slip is not less than $s_{3}$, there will be no shear stress in the interface, which means that the interface is completely decoupled (Figure 19, $s>s_{3}$ section). 


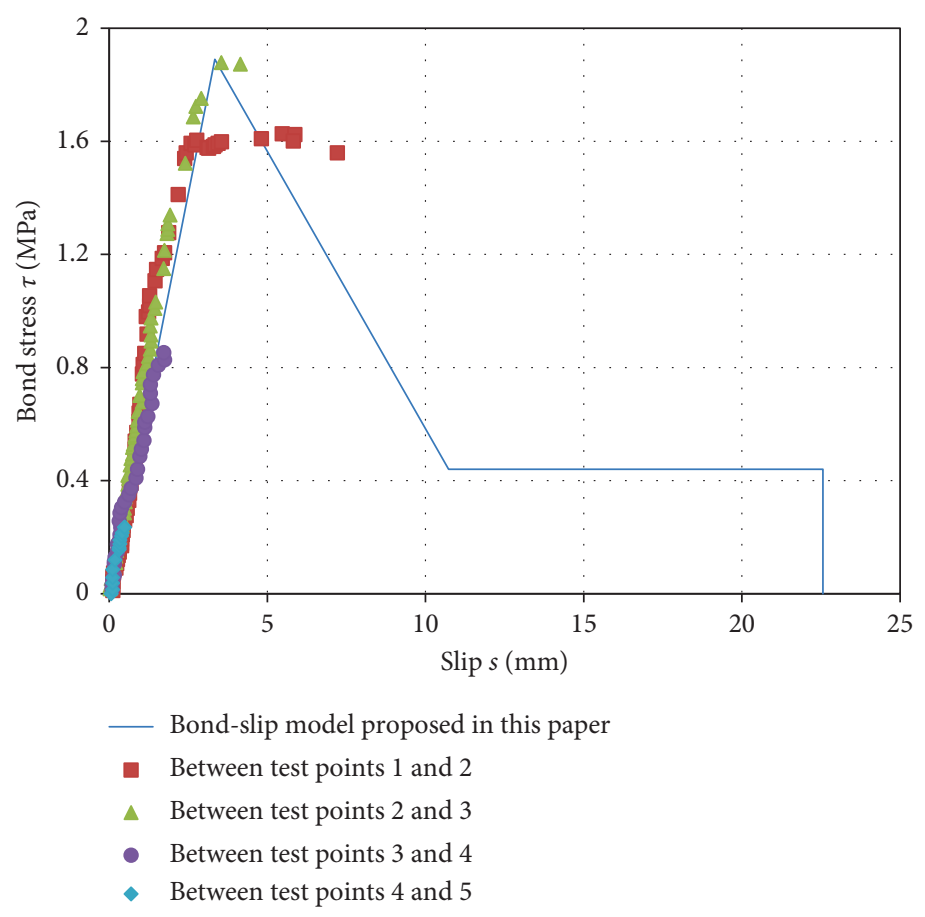

(a)

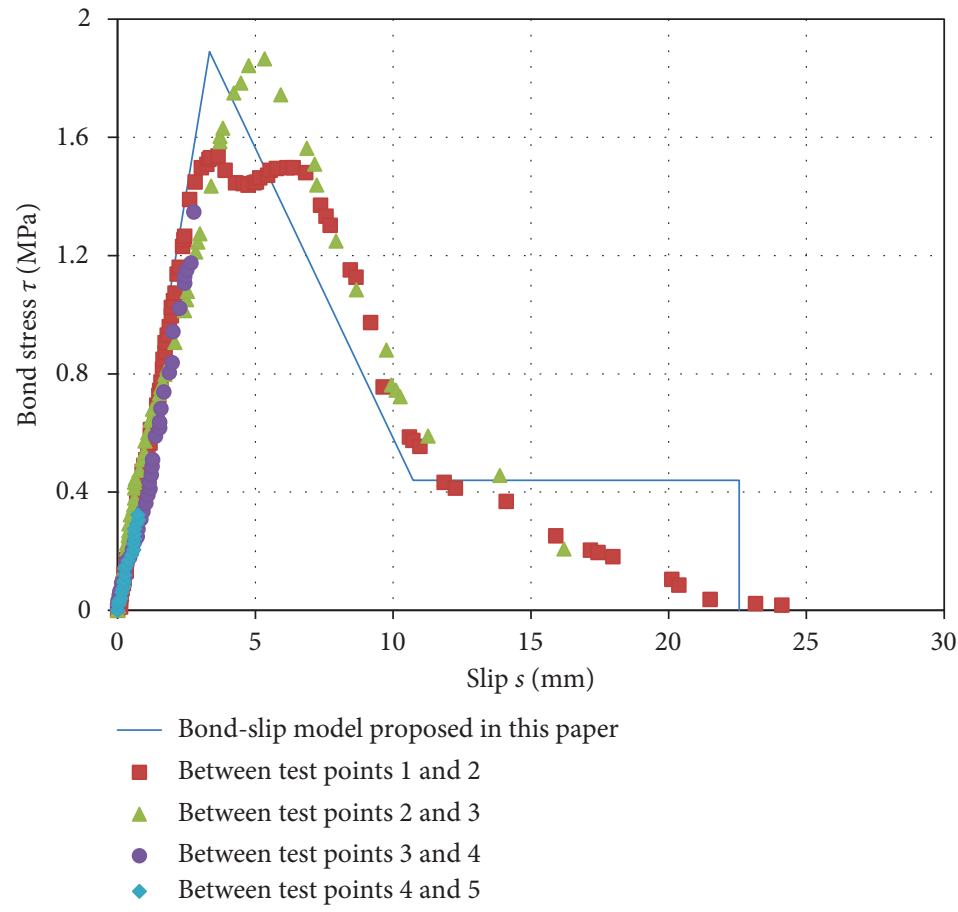

(b)

FIGURE 20: The comparison of the measured data of sheer stress and slip between bamboo-modified slurry interface bond-slip models at different anchorage depths. (a) Anchorage length $L<L_{\text {eff }}$ (CB-L-1500b). (b) Anchorage length $L \geq L_{\text {eff }}$ (CB-L-2000a).

\section{Modification of the Trilinear Bond-Slip Model}

Table 9 shows the bond-slip model of the interface between bamboo and modified slurry, which is determined according to the above method. All parameters were calculated on the basis of the average of the test data of the long bolt ( $2 \mathrm{~m}$ and $3 \mathrm{~m}$ ) samples.

Figure 20 shows the comparison of the measured data of the bamboo bolt-modified slurry interface with the modified bond-slip model drawn from Table 9. The data in Figure 20 are collected from the test results of specimens (CB-L-1500b 


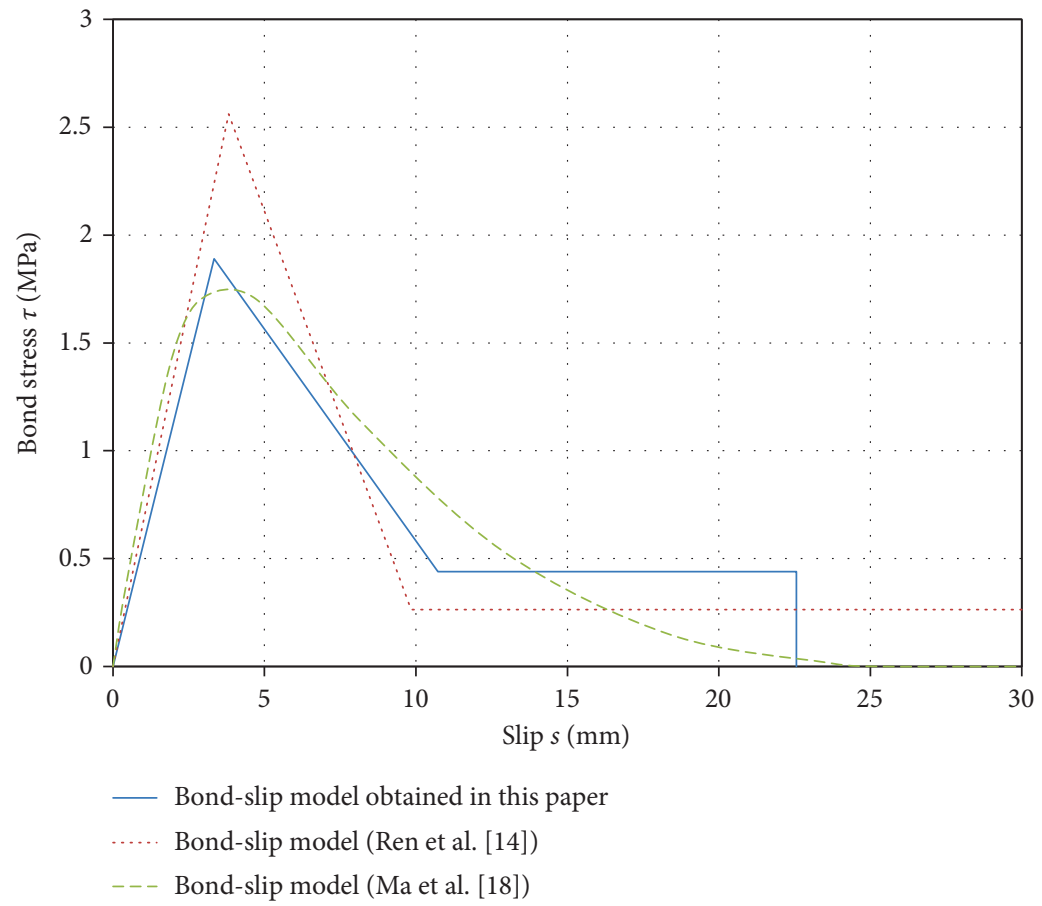

FiguRE 21: Comparison between the bond-slip model proposed in this paper and the bond-slip models obtained by the method of Ren et al. [14] and Ma et al. [18].

and CB-L-2000a) and presented, respectively, according to the relationship between the anchorage length $(L)$ and effective anchorage length $\left(L_{\text {eff }}\right)$, that is, whether the former exceeds the latter.

It can be seen from Figure 20 that the shear stress of the elastic segment of this type of interface increases rapidly with the slip amount and the area of the linear softening area is larger than that of the elastic region, which indicates that the energy dissipation capacity of the softening section is larger than that of the elastic section, and the energy dissipation effect of the residual stress section cannot be ignored. When the slip amount is too large, the interface shear stress is almost zero. Since the interface shear stress decreases linearly with the increase of slip amount, the residual stress section can maintain a certain residual shear stress, such an interface generally has a long effective bond length, which is determined by the interface bond-slip model and material properties. Since the total energy released during the bond-slip process is determined by the bond-slip model (e.g., bamboo-modified slurry interface $G_{f}=16.97 \mathrm{~N} / \mathrm{mm}$ ), when the anchorage length exceeds the effective anchorage length $\left(L_{b} \geq L_{\text {eff }}\right)$, the maximum anchoring force is constant and the effect of increasing the anchoring length on the anchoring force is limited.

\section{Bond-Slip Model Verification}

Figure 21 shows the comparison between the bond-slip model proposed in this paper and the bond-slip models obtained by the method of Ren et al. [14] and Ma et al. [18]. It can be seen that the model proposed in this paper fits well into what obtained by the method of Ma et al., and both of them fully considered the complete decoupling phenomenon.
However, as the calculation of the nonlinear model is complicated, it is restricted in actual engineering applications. Using the method of Ren et al., the maximum bonding strength of the interface will be overestimated, thus resulting in hidden danger to the anchorage system.

\section{Conclusions}

The bond-slip behavior of the bamboo-modified slurry interface is analyzed by the in situ pull-out test, and the slip, stress, and strain distribution of the interface in the axial direction of the bolt is obtained. Then, the strain-slip curve characteristics of the interface are analyzed. Finally, the improved trilinear bond-slip model of the bamboo boltmodified slurry interface is put forward, according to the relationship between the strain-slip curve and trilinear bond-slip model. The following conclusions are reached:

(1) The main failure mode of the anchorage system is the bamboo bolt-modified slurry interface slip failure, of which the slip is about 10-50 times that of the modified slurry-soil interface. Bamboo-modified slurry interface bonding strength is relatively low, only about $6 \% \sim 23 \%$ of the bamboo strength is motivated.

(2) Bamboo-modified slurry bonding interface still has the characteristics of trilinear bond-slip model when the slip amount is small, energy consumption is mainly done by the softened segment, and it has certain flexibility characteristics.

(3) When the anchorage length exceeds the effective anchorage length and slip amount is large, there is a complete decoupling phenomenon. At this time, 
the interface bond stress is almost zero, the effective bond length has a certain value, and the ultimate anchoring force cannot grow with the increase of anchorage length.

(4) The model proposed in this paper is based on the trilinear bond-slip model, which takes the interface complete decoupling phenomenon into account and corrects the interface shear stress when the slip exceeds $s_{3}$. The model curve is in a closed area with the coordinate axis. Therefore, the total energy consumption of the bond-slip process (such as bamboo-modified slurry interface $G_{f}=16.97 \mathrm{~N} / \mathrm{mm}$ ) can be determined by the bond-slip model.

(5) The model proposed in this paper fits well into test results. Compared with the method of Ren et al., the peak bonding strength of the interface can be estimated more accurately via this mode. Moreover, the model proposed in this paper is easier to use than the model proposed by Ma et al.

\section{Conflicts of Interest}

The authors declare that there are no conflicts of interest regarding the publication of this paper.

\section{Authors' Contributions}

Wei Lu conceived the study and wrote the paper. Mao Xiaofei carried out the experiments and data analysis. Dong Zhao led the projects and reviewed the manuscript.

\section{References}

[1] Z. X. Li, L. Y. Zhao, and M. L. Sun, "Deterioration of earthen sites and consolidation with PS material along Silk Road of China," Chinese Journal of Rock Mechanics and Engineering, vol. 28, no. 5, pp. 1047-1054, 2009, Chinese.

[2] W. W. Chen, Z. Q. Guo, Y. R. Xu, and F. Ye, "Laboratory tests on rammed earth samples of earthen sites instilled by reinforcement material SH," Chinese Journal of Geotechnical Engineering, vol. 37, no. 8, pp. 1517-1523, 2015, Chinese.

[3] K. Watanabe, M. M. Maung, Y. Fujii, and E. Fodde, "Evaporation of historical Buddhist Monastery Ajina Tepa, Tajikistan," Proceedings of Hydraulic Engineering, vol. 52, pp. 19-24, 2008.

[4] D. Zhao, W. Lu, Y. L. Wang, X. F. Mao, Y. Ai, and H. T. Jiang, "Experimental studies on earthen architecture sites consolidated with BS materials in arid regions," Advances in Materials Science and Engineering, vol. 2016, Article ID 6836315, 13 pages, 2016.

[5] M. L. Sun, X. D. Wang, Z. X. Li, and W. W. Chen, "Study on immature earthen sites reinforced with wood anchor," Chinese Journal of Geotechnical Engineering, vol. 28, no. 12, pp. 2156-2159, 2006, Chinese.

[6] Y. L. Wang, D. Zhao, F. Lei, and W. X. Zhang, "The deterioration inspection and cause analysis for Mingjing Tai," Electronic Journal of Geotechnical Engineering, vol. 21, no. 7, pp. 1659-1680, 2016.

[7] P. G. Fuller and R. G. Hume, "Bolt load simulation and its practical application," in Rock Mechanics, Aubertin, Hassani, and Mitri, Eds., A. A. Balkema, Rotterdam, Netherlands, 1996, ISBN:90 $5410838 \mathrm{X}$.

[8] I. W. Farmer, "Stress distribution along a resin grouted rock anchor," International Journal of Rock Mechanics and Mining Sciences \& Geomechanics Abstracts, vol. 12, no. 11, pp. 347351, 1975.

[9] S. Yazici and P. K. Kaiser, "Bond strength of grouted cable bolts," International Journal of Rock Mechanics and Mining Sciences \& Geomechanics Abstracts, vol. 29, no. 3, pp. 279292, 1992.

[10] B. Benmokrane, A. Chennouf, and H. S. Mitri, "Laboratory evaluation of cement-based grouts and grouted rock anchors," International Journal of Rock Mechanics and Mining Sciences \& Geomechanics Abstracts, vol. 32, no. 7, pp. 633-642, 1995.

[11] C. Li and B. Stillborg, "Analytical models for rock bolts," International Journal of Rock Mechanics and Mining Sciences, vol. 36, no. 8, pp. 1013-1029, 1999.

[12] A. Fahimifar and H. Soroush, "A theoretical approach for analysis of the interaction between grouted rockbolts and rock masses," Tunnelling and Underground Space Technology, vol. 20, no. 4, pp. 333-343, 2005.

[13] Z. M. Wu, S. T. Yang, X. Z. Hu, and J. J. Zheng, "Analytical method for pullout of anchor from anchor-mortar-concrete anchorage system due to shear failure of mortar," Journal of Engineering Mechanics, vol. 133, no. 12, pp. 1352-1369, 2007.

[14] F. F. Ren, Z. J. Yang, J. F. Chen, and W. W. Chen, "An analytical analysis of the full-range behavior of grouted rockbolts based on a tri-linear bond-slip model," Construction and Building Materials, vol. 24, pp. 361-370, 2010.

[15] S. Q. Ma, Z. Y. Zhao, W. Nie, and Y. L. Gui, "A numerical model of fully grouted bolts considering the Tri-linear shear bond-slip model," Tunnelling and Underground Space Technology, vol. 54, pp. 73-80, 2016.

[16] L. B. Martín, M. Tijani, and F. Hadj-Hassen, "A new analytical solution to the mechanical behavior of fully grouted rock bolts subjected to pull-out tests," Construction and Building Materials, vol. 25, no. 2, pp. 749-255, 2011.

[17] H. C. Biscaia, C. Chastre, and M. A. G. Silva, "Linear and nonlinear analysis of bond-slip models for interfaces between FRP composites and concrete," Composites Part B: Engineering, vol. 45, no. 1, pp. 1554-1568, 2013.

[18] S. Q. Ma, J. Nemcik, and N. Aziz, "An analytical model of fully grouted rock bolts subjected to tensile load," Construction and Building Materials, vol. 49, pp. 519-526, 2013.

[19] N. Wang, J. K. Zhang, W. W. Chen, Z. X. Li, and M. L. Sun, "Anchor performance of wood bolt fully grouted by natural hydraulic lime and quartz sand slurry," Journal of Civil, Architectural \& Environmental Engineering, vol. 37, no. 3, pp. 86-93, 2015, Chinese.

[20] J. K. Zhang, W. W. Chen, Z. X. Li, X. D. Wang, and F. G. He, "Anchorage performance and interfacial mechanics transfer characteristics of composite bolt with double-strand," Journal of Central South University, vol. 45, no. 2, pp. 563-569, 2014, Chinese.

[21] CECS22: 90, Code for Design and Construction of Soil Anchor, China Metallurgical Construction Research Institute, Beijing, China, 1991, Chinese.

[22] GB 50330-2013, Technical Code for Building Slope Engineering, China Building Industry Press, Beijing, China, 2013, Chinese.

[23] GB/T50123-1999, Standard for Soil Test Method, China Planning Press, Beijing, China, 1999, Chinese.

[24] GB/T 15780-1995, Testing Methods for Physical and Mechanical Properties of Bamboos, China Standard Press, Beijing, China, 1996, Chinese. 
[25] JG/T 199-2007, Testing Method for Physical and Mechanical Properties of Bamboo Used in Building, China Standard Press, Beijing, China, 2007, Chinese.

[26] J. K. Zhang, Q. L. Guo, Z. X. Li et al., Preliminary Study on Anchorage Mechanism of Earthen Sites, Lanzhou University Press, Lanzhou, China, 2014, Chinese.

[27] J. K. Zhang, W. W. Chen, Z. X. Li et al., "Field tests on anchorage mechanism of wood bolts for conservation of earthen sites," Chinese Journal of Geotechnical Engineering, vol. 35, no. 6, pp. 1166-1171, 2013, Chinese.

[28] J. K. Zhang, N. Wang, F. Meng et al., "Anchor performance of bamboo bolt grouted by PS solution-based slurry among rammed earth medium," Journal of Engineering Geology, vol. 24, no. 5, pp. 1028-1036, 2016, Chinese.

[29] J. K. Zhang, W. W. Chen, Z. X. Li et al., "Analysis of in-situ anchoring characteristics of composite anchor containing steel bar ( $422 \mathrm{~mm})$, , Rock and Soil Mechanics, vol. 35, no. 11, pp. 3139-3147, 2014, Chinese.

[30] J. K. Zhang, W. W. Chen, F. G. He et al., "Field experimental study on anchorage performance of GFRP at conservation earthen sites," Journal of Engineering Geology, vol. 22, no. 5, pp. 804-810, 2014, Chinese.

[31] S. Matthys, "Structural behavior and design of concrete members strengthened with externally bonded FRP reinforcement," Ph.D. thesis, Department of Structural Engineering, Ghent University, Ghent, Belgium, 2000.

[32] K. Nakaba, T. Kanakubo, T. Furuta, and H. Yoshizawa, "Bond behavior between fiber-reinforced polymer laminates and concrete," ACI Structural Journal, vol. 98, no. 3, pp. 359-367, 2001.

[33] J. Dai, T. Ueda, and Y. Sato, "Development of the nonlinear bond stress-slip model of fiber reinforced plastics sheetconcrete interfaces with a simple method," Journal of Composites for Construction, vol. 9, no. 1, pp. 52-62, 2005.

[34] C. Faella, E. Martinelli, and E. Nigro, "Interface behavior in FRP plates bonded to concrete: experimental tests and theoretical analyses," in Proceedings of ECI Conference on Advance Materials for Construction of Bridges, Buildings, and Other Structures III, Davos, Switzerland, 2003.

[35] H. C. Biscaia, C. Chastre, I. S. Borba, C. Silva, and D. Cruz, "Experimental evaluation of bonding between CFRP laminates and different structural materials," Journal of Composites for Construction, vol. 20, no. 3, Article ID 04015070, 2016.

[36] J. J. Zheng and J. G. Dai, "Prediction of the nonlinear pull-out response of FRP ground anchors using an analytical transfer matrix method," Engineering Structures, vol. 81, pp. 377-385, 2014.

[37] H. C. Biscaia, C. Chastre, and M. A. G. Silva, "Double shear tests to evaluate the bond strength between GFRP/concrete elements," Composite Structure, vol. 94, no. 2, pp. 681-694, 2012. 